\title{
Short term interactions between tree foliage and the aerial environment: An overview of modelling approaches available for tree structure-function models
}

\author{
Hervé Sinoquet* and Xavier Le Roux \\ UMR PIAF, INRA - Université Blaise Pascal, Site de Crouelle, 234 avenue du Brézet, \\ 63039 Clermont-Ferrand Cedex 02, France
}

(Received 9 March 1999; accepted 4 November 1999)

\begin{abstract}
Functional-structural tree models represent tree/aboveground environment interactions. Actually, plant architecture and function induce large variations in environmental variables within the canopy, while these variations themselves induce a range of responses at the organ scale which modulate plant function and architecture dynamics. This paper gives an overview of (i) processes involved in the short-term interactions between the tree foliage and the aboveground environment and (ii) associated modelling approaches. Then, it is shown that detailed models of tree foliage/aboveground environment interactions can be used to test simplifying assumptions such as the constancy of light or water use efficiency recently used in several functional-structural tree models. We conclude that a good knowledge of basic processes involved in these short-term interactions is available. The point is now to compare models focusing on tree-atmosphere exchanges, and to use these models to test assumptions and derive summary submodels for tree functional-structural models.
\end{abstract}

microclimate / radiation / wind / photosynthesis / transpiration / acclimation / modelling / integration

Résumé - Interactions à court terme entre le feuillage de l'arbre et son environnement aérien : une revue des approches de modélisation disponibles pour les modèles d'arbre structure-fonction. Les modèles d'arbres structure - fonction représentent les interactions entre l'arbre et son environnement aérien. En effet, la présence et le fonctionnement de la plante induisent de grandes variations des variables climatiques dans le couvert, et ces variations du microclimat peuvent elles mêmes moduler les réponses de la plante à l'échelle de l'organe (et donc son fonctionnement et son développement). Cet article présente une revue critique des mécanismes impliqués à court terme dans les interactions entre le feuillage de l'arbre et son environnement microclimatique, ainsi que les approches proposées pour leur modélisation. Il est ensuite montré que des modèles détaillant les interactions entre l'arbre et son environnement aérien peuvent servir à tester des hypothèses simplificatrices du fonctionnement de l'arbre, comme la constance de l'efficience d'utilisation de la lumière ou de l'eau. Nous concluons que les processus impliqués dans ces interactions sont assez bien connus. Il faut maintenant comparer les modèles de simulation des échanges plante-atmosphère, et développer des modèles simples qui puissent être intégrés dans les modèles dynamiques structure-fonction.

microclimat / rayonnement / vent / photosynthèse / transpiration / acclimatation / modélisation / intégration

* Correspondence and reprints

Tel. 04736243 61; Fax. 04736244 54; e-mail: sinoquet@clermont.inra.fr 


\section{INTRODUCTION}

Interactions between trees and the environment have been extensively studied for their consequences for both the tree and the environment. From the tree point of view, growth and development processes are closely related to resource availability (light, water, carbon, nutrients, heat). Organs of the same tree may be subject to contrasting environmental conditions, and this may result in differential responses which may have consequences on growth and morphology at the whole tree scale. From the environment point of view, trees act as modifiers of both soil properties and microclimate variables. This may be due simply to the presence of the tree (e.g. wind attenuation) or also due to tree functioning (e.g. increase of air humidity due to transpiration). Such effects of trees on microclimate have been used for environmental purposes such as carbon sequestration in a global change perspective [40], or fuel economy and pollutant capture in urban environment [50,85].

The framework of tree structure - function models is primarily aimed at understanding tree growth and development. Functional-structural tree models generally have to represent several processes and to account for the interactions occurring between these processes. Two kinds of models can be distinguished here: i) static models where tree structure is a model input and assumed not to change. These models mainly deal with instantaneous processes involved in resource acquisition and use (e.g. transpiration and/or photosynthesis) and study the interactions between these processes and tree architecture; ii) dynamic models aimed at simulating tree architecture dynamics as the result of the interactions between tree structure, function and the environment. Such models are structural-functional tree models sensu stricto and should include both instantaneous and delayed tree responses to the environment.

In both static and dynamic structural - functional tree models, the tree is represented by a collection of organs that can be defined at several scales [53]. Tree organs interact with each other through physical connections (i.e. tree topology) which allows them to internally exchange substances (e.g. see [77]). They also interact with the environment as a function of their spatial distribution and functioning. Such a framework implies a spatial distribution of both the environmental conditions (i.e. the effect of the tree on microclimate) and the tree responses (i.e. at a local scale).

This paper aims to provide a comprehensive review of (i) the processes involved in the short-term interactions between the tree foliage and the aboveground environment and (ii) the way these interactions are represented in functional-structural tree models. Such processes mainly involve the spatial distribution of leaf area. This is the reason why any model dealing with the spatial distribution of processes within the canopy have been included in the review. In contrast, "big leaf" models are not in the scope of this overview because they do not account for spatial distribution. Due to the rather large scope, only short-term plant responses involved in aerial resource acquisition are considered, namely stomatal conductance, photosynthesis and transpiration. In particular, tree responses in terms of phenology, primary and secondary growth, flowering and reproduction are disregarded. The (potentially important) interactions between tree structure, tree function and aerial phytopathogens are also beyond the scope of this review. Notice that tree belowground interactions are reviewed by Pagès et al., this issue.

The first and second section of the paper deal with leaf responses to the aerial environment and environmental changes due to tree structure and function, respectively (figure 1). Due to the large topic, these sections are rather an overview than a true review of existing knowledge and modelling approaches. The third section is devoted to the representation of those processes in the structural - functional tree models, both static and dynamic. Detailed models of tree foliage-environment

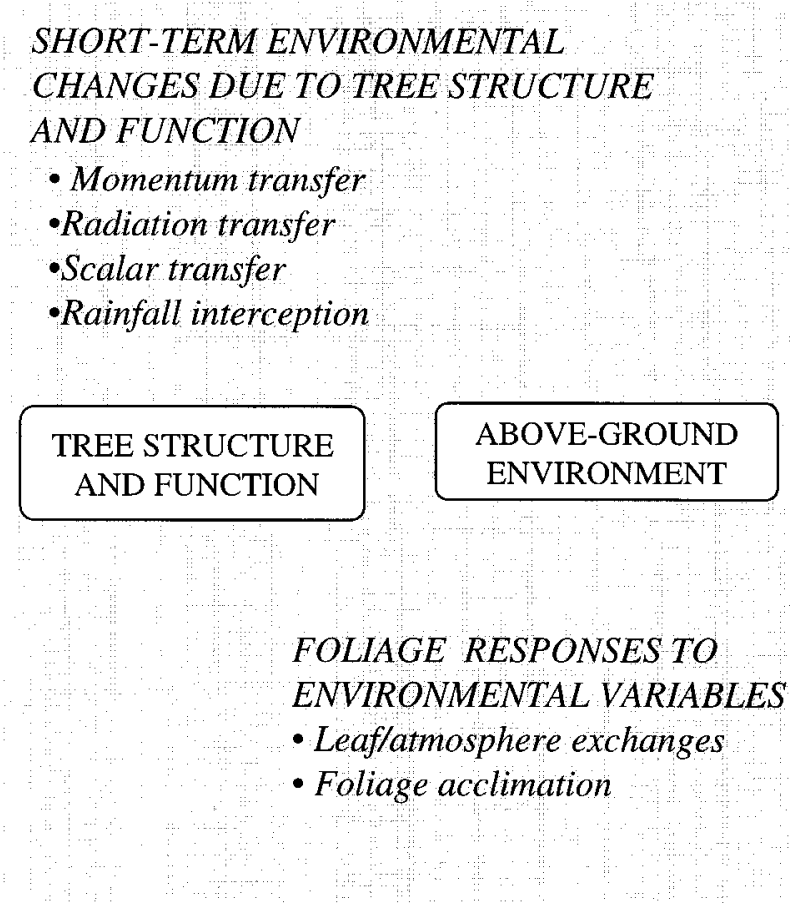

Figure 1. Schematic representation of the interactions between tree structure, tree function and the aboveground environment. 
interactions are generally inadequate for simulations over long-term periods (as required by models predicting tree architecture dynamics for instance). However, in the fourth section, it is shown that such detailed models can be used to test a number of simplifying assumptions such as the constancy of light or water use efficiency recently used in several functional-structural models of tree growth and development.

\section{LEAF RESPONSES TO ENVIRONMENTAL VARIABLES}

\subsection{Instantaneous leaf responses to aboveground environmental variables}

Short-term variations in the aboveground environment induce instantaneous responses of several physiological processes at leaf level, namely stomatal conductance, transpiration and photosynthesis.

\section{Stomatal function}

Although the physiology of stomata has been extensively studied, the mechanisms regulating stomatal behaviour are still poorly understood. Firstly, the roles of air relative humidity, air vapour pressure deficit or whole-leaf transpiration rate are still debated [e.g. 1, 15, 55, 89, 93, 95]. Furthermore, stomata have also been assumed to respond to hydrostatic signals and to signals transmitted by abscisic acid [e.g. 15, 27, 55, 130], but the relative importance of hydraulic and chemical signals is still unclear (see the review by Whitehead [138]). The response of stomata to environment is traditionally viewed as a "feedforward" response, i.e. where conductance responds to environmental factors that affect the transpiration rate [44]. In contrast, Monteith [93] reinterpreted data on stomatal responses to vapour pressure deficit (VPD) and concluded that there is a "feedback" response of whole-leaf transpiration rate on stomatal conductance. Alternatively, according to Wong et al. [142], stomata can sense the intercellular $\mathrm{CO}_{2}$ concentration which depends on leaf photosynthesis. This way, conductance can be viewed as a slave of leaf photosynthesis. Finally, changes in stomatal conductance can also be viewed as a way to avoid xylem embolism [124, 135].

Due to the poor understanding of the mechanisms regulating stomatal behaviour, no unique modelling approach has emerged to account for stomatal response to environmental conditions. However, four major approaches can be identified (Monteith's feedback model has not been used so far in functional-structural tree models, and models representing the co-ordination between stomatal conductance and hydraulic architecture have not been widely used in the context of structuralfunctional tree models, but see the modelling framework proposed by Jones and Sutherland [69]). The first approach does not link stomatal conductance and photosynthesis, while the second and third approaches exploit this linkage. The fourth approach can be viewed as a simple, empirical expression resulting from assumptions made in the third approach.

First, Jarvis [66] proposed a phenomenological model for simulating stomatal conductance. Assuming that the stomatal conductance $g_{\mathrm{s}}$ is affected by non-synergistic interactions between plant and environmental variables, this model computes $g_{\mathrm{s}}$ as

$$
g_{\mathrm{s}}=g_{\text {smax }} f(\mathrm{PAR}) f(\mathrm{VPD}) f\left(C_{\mathrm{s}}\right) f\left(T_{1}\right) f(\Psi)
$$

where PAR is the leaf irradiance, VPD is the air water vapour pressure deficit at the leaf surface, $C_{\mathrm{s}}$ is the air $\mathrm{CO}_{2}$ concentration at the leaf surface, $T_{1}$ is leaf temperature, $\Psi$ is the shoot water potential, and $g_{\text {smax }}$ is the maximum stomatal conductance. This approach offers a simple, convenient modelling framework to identify the relative importance of each variable on $g_{s}$. However, the basic assumption of this multiplicative model has rarely been tested (e.g. [9]). In most cases, users document the stomatal responses to PAR, VPD, $T_{1}$ and $C_{\mathrm{s}}$ by applying a non-linear optimisation technique on available data sets covering a range of natural environmental conditions encountered during several diurnal cycles.

An alternative, optimisation approach of stomatal function was proposed by Cowan and Farquhar [28]. During a given time period, optimising the cost of water loss for $\mathrm{CO}_{2}$ acquisition implies that stomatal aperture should change with time so that the gain ratio remains constant

$$
\left(\partial \mathrm{E} / \partial g_{\mathrm{s}}\right) /\left(\partial \mathrm{A} / \partial g_{\mathrm{s}}\right)=\lambda
$$

The optimisation theory is appealing because, as deterministic approaches, it can predict unique characteristics of leaf gas exchanges such as the midday stomatal depression. However, the approach shares the drawbacks of other goal-seeking approaches, and is unable to prescribe a unique optimisation coefficient.

A third approach is Ball's empirical model [6]. This formulation directly relates stomatal conductance to leaf photosynthetic rate

$$
g_{\mathrm{s}}=m A h / C_{\mathrm{s}}+b
$$

where $h$ is air relative humidity, and $m$ and $b$ are parameters. A modified version of this model was proposed by Leuning [81] and interpreted in terms of guard cell function [38]. This approach is attractive since it requires fewer tunable parameters than the Jarvis model for 
instance. Aphalo and Jarvis [2] concluded that this model is useful for describing changes in intercellular $\mathrm{CO}_{2}$ concentration and can be used as a submodel in models of canopy functioning, but it cannot be viewed as a mechanistic model.

In some cases, the ratio of the partial pressure of $\mathrm{CO}_{2}$ in the intercellular air spaces to the partial pressure of $\mathrm{CO}_{2}$ at the leaf surface $C_{\mathrm{i}} / C_{\mathrm{s}}$ is computed by an empirical function of leaf irradiance PAR and VPD (e.g. [144])

$$
C_{\mathrm{i}} / C_{\mathrm{s}}=f(\mathrm{PAR}, \mathrm{VPD}) \text {. }
$$

This approach can be used if stomatal conductance has not to be computed explicitly (i.e. in tree models focusing on carbon gains which do not represent transpiration losses).

\section{Transpiration}

Because transpiration can be regarded as a physical process, all transpiration models use the same basic approach, i.e. the energy balance (e.g. see [94])

$$
R n+M=H+\lambda E
$$

where $R n$ and $M$ are the net gains of energy from radiation and metabolism, respectively, and $H$ and $\lambda E$ are losses of sensible and latent heat, i.e. by convection and evaporation, respectively. $R n$ can be estimated from radiative transfer models (see below) which include the treatment of thermal infrared radiation, i.e. radiation emission by vegetation. $M$ is generally neglected because it only accounts for a few percent of energy gains. $H$ and $\lambda E$ are computed from flux-gradient relationships

$$
\begin{aligned}
& H=\rho \cdot c_{\mathrm{p}} \cdot g_{\mathrm{b}} \cdot\left(T_{\mathrm{s}}-T_{\mathrm{a}}\right) \\
& \lambda E=\frac{\rho \cdot c_{\mathrm{p}}}{\gamma} \cdot g_{\mathrm{w}} \cdot\left(e_{\mathrm{s}}-e_{\mathrm{a}}\right)
\end{aligned}
$$

where $\rho, c_{\mathrm{p}}, \gamma$ are the air density $\left(\mathrm{kg} \mathrm{m}^{-3}\right)$, the heat capacity of the air $\left(\mathrm{J} \mathrm{kg}^{-1} \mathrm{~K}^{-1}\right)$, and the psychrometric constant $\left(\mathrm{Pa} \mathrm{K}^{-1}\right)$, respectively. $T_{\mathrm{s}}$ and $T_{\mathrm{a}}$ are air and leaf temperatures, and $e_{\mathrm{s}}$ and $e_{\mathrm{a}}$ are the water vapour pressure in the substomatal spaces and in the air, respectively. Conductances $g_{\mathrm{b}}$ and $g_{\mathrm{w}}\left(\mathrm{m} \mathrm{s}^{-1}\right)$ relate to the leaf boundary layer and to water transport from the sub-stomatal spaces to the air. Vapour pressure is assumed to be saturating in sub-stomatal spaces. Conductance $g_{\mathrm{b}}$ is a function of local wind speed while $g_{\mathrm{w}}$ includes both stomatal and leaf boundary layer conductances (see e.g. [94]). Modelling transpiration requires the solution of the system of equations $(5,6,7)$. An analytical solution was provided by Penman [108] for the case of wet surfaces (i.e. $g_{\mathrm{w}}=g_{\mathrm{b}}$ ) and Monteith [91] further included the effect of stomatal conductance, leading to the classical Penman-Monteith combination equation

$$
\lambda E=\frac{s \cdot R n+\rho \cdot c_{\mathrm{p}} \cdot g_{\mathrm{b}} \cdot D_{\mathrm{a}}}{s+\gamma\left(1+\frac{g_{\mathrm{b}}}{g_{\mathrm{s}}}\right)}
$$

where $s$ is the slope of the saturation vapour pressure curve with respect to temperature and $D_{\mathrm{a}}$ is vapour pressure deficit of the air. Mc Naughton and Jarvis [87] rewrote the Penman-Monteith equation as

$$
\lambda E=\Omega \cdot \lambda E_{\mathrm{eq}}+(1-\Omega) \cdot \lambda E_{\mathrm{imp}}
$$

where $\Omega$ is a dimensionless "decoupling" factor $(0<\Omega<1), \lambda E_{\mathrm{eq}}$ is the equilibrium evaporation rate and $\lambda E_{\mathrm{imp}}$ is the imposed evaporation rate. $\lambda E_{\mathrm{eq}}$ depends only on available energy (i.e. $R n$ ) while $\lambda E_{\text {imp }}$ depends on surface conductance and water vapour deficit (see [67]). The decoupling factor $\Omega$ makes explicit the relative contribution of $\lambda E_{\text {eq }}$ and $\lambda E_{\text {imp }}$ to actual transpiration $\lambda E$. It depends on the relative magnitude of leaf boundary and stomatal conductances (see [67]). For tree canopies (temperate forests [87, 88], mediterranean oak-savannas $[65]), \Omega$ values computed at canopy scale are low $(\approx 0.2)$ due to the large boundary layer conductance with regard to surface conductance. This observation led Infante et al. [65] to approximate $\lambda E$ by the only term $\lambda E_{\mathrm{imp}}$. However, Daudet et al. [29] showed significant variations of $\Omega$ values within the crown of an isolated tree, i.e. ranging from 0.2 to 0.6 .

As an alternative to the Penman-Monteith solution (Eq. 8), numerical methods can also be used to solve the energy balance equation. This allows to take into account explicitly the effect of leaf temperature on every variable affecting the energy balance, namely radiation emission by the leaf surface, the saturation vapour pressure in the sub-stomatal space, and stomatal conductance. All terms of the energy balance (i.e. $R n, H$ and $\lambda E)$ are thus leaf temperature-dependent. Leaf temperature thus appears as the tuning variable of the energy balance, i.e. the variable to be computed from equation (5). Due to the non-linearity of equation (5) with respect to temperature, a numerical solution involves iterative processes, such as the Newton-Raphson method (see [100]).

\section{Photosynthesis}

In contrast to stomatal conductance, there is a general consensus on the way environmental variables affect leaf photosynthesis [45]. Leaf photosynthesis instantaneously responds to a few environmental variables such as light 
intensity, temperature, air $\mathrm{CO}_{2}$ concentration and air pollutants. This response reflects changes in both stomatal conductance and mesophyll capacity which depends on the activity of Rubisco and on the capacity for electron transport to regenerate $\mathrm{RuP}_{2}$. Light has a key role by providing the energy transduced in the electron transport chain and thus can restrict $\mathrm{RuP}_{2}$ regeneration, while $\mathrm{CO}_{2}$ can limit $\mathrm{RuP}_{2}$ carboxylation. Leaf temperature strongly influences photosynthetic rates, essentially through its effect on enzymatic activity and Rubisco specificity [70].

Three approaches can be distinguished as far as photosynthesis formulation is concerned. In the first approach, leaf photosynthesis is not computed explicitly. Instead, the model computes photosynthate production $P$ as proportional to leaf mass $W_{1}$ or area $A_{1}$ (e.g. [84]), or to absorbed radiation PAR $_{\mathrm{a}}$ according to Monteith's model [92]

$$
\begin{gathered}
P=\sigma_{1} W_{1} \quad \text { or } \quad P=\sigma_{1} A_{1} \\
P=\text { LUE PAR }_{\mathrm{a}}
\end{gathered}
$$

where $\sigma_{1}$ is the leaf specific activity $\left(\mathrm{gC} \mathrm{g}^{-1}\right.$ or $\left.\mathrm{gC} \mathrm{m}^{-2}\right)$ and LUE is the light use efficiency $\left(\mathrm{gC} \mathrm{MJ}^{-1}\right)$. An alternative, simple approach [34] is to assume that $P$ is proportional to transpiration $\left(E, \mathrm{~kg} \mathrm{H}_{2} \mathrm{O}\right.$ unit time $\left.{ }^{-1}\right)$, so that

$$
P=\text { WUE } E
$$

where WUE is the prescribed water use efficiency $\left(\mathrm{gC} \mathrm{kg} \mathrm{H}_{2} \mathrm{O}^{-1}\right.$ ).

A second class of models simulate leaf photosynthesis A by empirical relationships such as

$$
A=A_{\text {max }} f(\mathrm{PAR}) g_{1}\left(T_{\mathrm{a}}\right) g_{2}\left(C_{\mathrm{a}}\right) g_{3}(\mathrm{VPD}) g_{4}(\Psi) g_{5}(\mathrm{~N})
$$

where $A_{\max }$ is the maximum leaf photosynthetic rate observed at saturating leaf irradiance PAR and in optimal environmental conditions, $f$ is an empirical function accounting for the effect of leaf irradiance, and $g$ represents a multiplicative function accounting for the effects of environmental parameters or leaf status such as air temperature $\left(T_{\mathrm{a}}\right)$ and $\mathrm{CO}_{2}$ concentration $\left(C_{\mathrm{a}}\right)$, air water vapour pressure deficit (VPD), plant water potential $(\Psi)$, and/or leaf nitrogen content $(\mathrm{N})$. The most common relationships for $f(\mathrm{PAR})$ are the rectangular (e.g. [64]) or non rectangular (e.g. [132]) hyperbola.

Twenty years ago, Farquhar et al. [45] proposed a biochemically-based approach to account for the effects of the major environmental variables on the main leaf photosynthetic processes. This model was designed to describe the photosynthetic rate of $C_{3}$ species as a function of leaf irradiance, intercellular $\mathrm{CO}_{2}$ concentration and leaf temperature. Leaf net $\mathrm{CO}_{2}$ assimilation rate (A, $\mu \mathrm{mol} \mathrm{CO} \mathrm{C}^{-2} \mathrm{~s}^{-1}$ ) can be expressed as

$$
A=\min \left(W_{\mathrm{c}}, W_{\mathrm{j}}\right)+R_{\mathrm{d}}
$$

where $W_{\mathrm{c}}\left(\mu \mathrm{mol} \mathrm{CO}_{2} \mathrm{~m}^{-2} \mathrm{~s}^{-1}\right)$ is the carboxylation rate limited by the amount, activation state and/or kinetic properties of Rubisco, $W_{\mathrm{j}}\left(\mu \mathrm{mol} \mathrm{CO} \mathrm{C}^{-2} \mathrm{~s}^{-1}\right)$ is the carboxylation rate limited by the rate of $\mathrm{RuP}_{2}$ regeneration, and $\mathrm{R}_{\mathrm{d}}\left(\mu \mathrm{mol} \mathrm{CO} \mathrm{CO}^{-2} \mathrm{~s}^{-1}\right)$ is the rate of $\mathrm{CO}_{2}$ evolution in light which results from processes other than photorespiration. Rubisco activity is likely to restrict assimilation rates under conditions of high irradiance and low $\mathrm{CO}_{2}$ concentration. $\mathrm{RuP}_{2}$ regeneration is likely to be limiting at low irradiance and when $\mathrm{CO}_{2}$ concentration is high. Introducing the effect of nitrogen on photosynthesis is straightforward in Farquhar's model since the three key parameters of the model (the maximum carboxylation rate $V_{\text {cmax }}$, the light-saturated rate of electron transport $J_{\max }$, and the dark respiration rate $R_{\mathrm{d}}$ ) are proportional to the amount of leaf nitrogen on an area basis (e.g. $[47,79]$ ). Because the Farquhar model requires the value of $\mathrm{CO}_{2}$ concentration in sub-stomatal cavities $\left(C_{\mathrm{i}}\right)$ as input, the model must be used in conjunction with a stomatal conductance module.

\section{Foliage responses to a fluctuating environment}

The term "instantaneous" response can be misleading, because it assumes permanent steady-state between leaf gas exchanges and environmental variables. The inertia of leaf responses can generally be neglected when variations of environmental variables are slow, but can become crucial when environmental variables exhibit high-frequency variations. For instance, in some environments (i.e. forest floor or within dense tree canopies), a substantial amount of total radiation flux can be received as short-lived episodes of high intensity, i.e. sunflecks. It has been shown that light induction of the photosynthetic apparatus is required to obtain significant amounts of carbon fixation [18]. The kinetics of the response of leaf gas exchanges to sunflecks, and thus the efficiency of sunfleck utilisation differ markedly between tree species (e.g. [136]), depending on several factors that operate at different time scales [105]. In a similar way, not just the actual value of temperature experienced by a tree, but also the rate of cooling is of paramount importance in determining plant responses to drops in non-freezing temperature (as reviewed by Minorsky [90]). Despite all these dynamic responses of tree functioning to environmental factors, leaf gas exchanges are generally treated by steady-state approaches in functional-structural tree models (see Sect. 3.1) because the errors due to a steady-state treatment of these exchanges are small compared to errors due to the treatment of other processes such as carbon allocation. 


\subsection{Delayed tree responses \\ to aboveground environmental variables}

In addition to their instantaneous effects on tree function, aboveground environmental variables such as light and temperature can also induce delayed responses of tree foliage.

Light regime influences morphological characteristics of both leaves and shoots. In particular, mean leaf surface and petiole length are often correlated to the local light regime (e.g. [98]). Concurrently, light interception properties of individual shoots depend on light regime (e.g. $[110,125,127])$. Shade shoots generally exhibit more horizontal foliage [86], more regular leaf dispersion ([110] figure 2a) and larger STAR (Shoot to Total Area Ratio [127]). Those features increase their efficiency for light capture (e.g. [63, 128]).

Several biochemical and physiological leaf characteristics are also strongly sensitive to the leaf light regime. In particular, specific leaf area (SLA), amount of nitrogen per unit leaf area $\left(N_{\mathrm{a}}\right)$ and leaf photosynthetic capacities are generally highly correlated with time integrated leaf irradiance (e.g. [41, 43, 78, 79, 114] figure 2b). Lower, shaded leaves of dense canopies usually exhibit low amount of nitrogen per area when compared to sunlit upper leaves. This results in an improved utilisation of leaf nitrogen for photosynthesis at the whole plant or canopy scale (e.g. [47, 62]). The light regime experienced during leaf ontogeny is crucial in determining the leaf structural features, but it has also been shown that the light environment experienced by a given bud during the previous year can strongly influence the characteristics of leaves derived from this bud in beech [42]. In the same species, shoot morphological attributes such as leaf number and total leaf area were reported to be largely determined by the light regime of the previous year, while leaf properties such as SLA and $N_{\mathrm{a}}$ are mainly determined by current-year light regime [75].

Furthermore, fully mature leaves can acclimate to changing (increasing or decreasing) light environments, although the ability to acclimate and the delay involved in acclimation vary strongly between species. While some species exhibit no ability of photosynthetic acclimation (e.g. Alocasia: [121]), fully mature leaves of other species exhibit substantial acclimation responses (e.g. $[11,12])$. Such acclimation can result from changes in anatomical features or photosynthetic capacities per unit cell volume, and generally depends on the extent to which damage due to photoinhibition can be recovered [107]. Furthermore, the time required for completion of acclimation seems to be higher in woody species (c.a. 45 days: $[7,11,12])$ than in herbs (4 to 14 days: $[22,46])$.

(a)

SHADED BRANCH

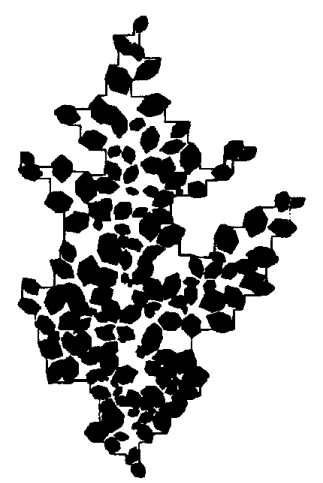

(b)

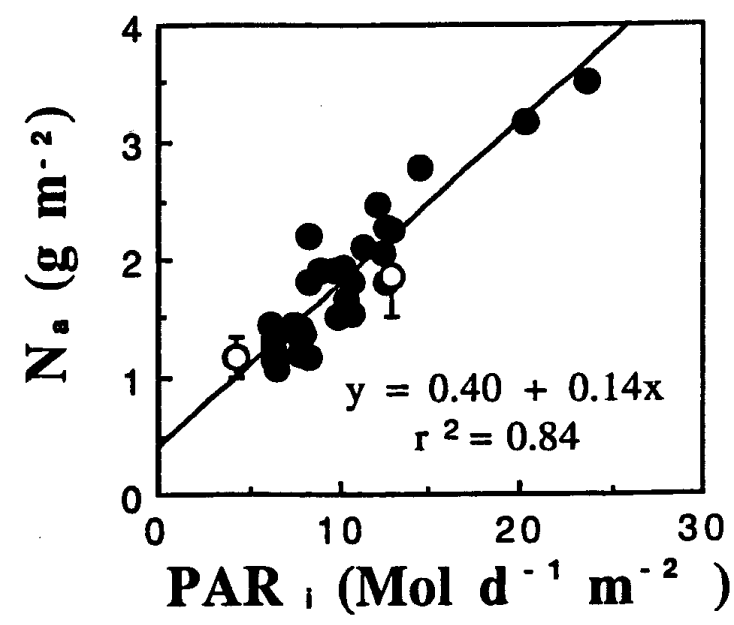

Figure 2. Illustration of some delayed tree responses to aboveground environment: (a) vertical projection of a shaded and a sunny branch from the middle part of a beech crown (after [110]); (b) relationship between the amount of nitrogen per unit leaf area and daily intercepted PAR for walnut leaves sampled within a mature tree and seedlings (after [78]).

Models of foliage acclimation to light are rare and mainly concern photosynthetic light acclimation, especially leaf nitrogen. Two approaches have been proposed so far, either empirical relationships between photosynthetic capacity, nitrogen per area, and time integrated leaf irradiance (e.g. [35]), or models of photosynthetic 
light acclimation based on the dynamics of starch, soluble sugars and soluble proteins pools [39, 133].

As with the light regime, the temperature experienced by tree foliage has long-term physiological implications. In particular, the temperature response of photosynthetic capacity strongly depends on growth temperature (e.g. [61]). To our knowledge no model of foliage acclimation to temperature is presently available.

\section{ABOVEGROUND ENVIRONMENTAL CHANGES DUE TO TREE STRUCTURE AND FUNCTION}

In the framework of tree structure-function models, plant-driven environmental changes mainly concern the spatial heterogeneity of microclimate variables induced by the presence of the tree. The aboveground environment includes variables related to energy (radiation, heat, momentum characterised by vertical and horizontal wind speed) and gas (water vapour, $\mathrm{CO}_{2}$ and other biogenic gases) content of the air. Heat and gas contents of the air are called "scalars" because they are characterised by a single variable, either temperature or gas concentration. The modification of microclimate is primarily due to the production and capture of energy and gases by the tree components.

\section{Representation of canopy architecture for simulating tree-environment interactions}

Microclimate modification depends on the resource field above the canopy, the surface properties of tree components, and tree architecture. With regard to tree architecture, light, wind and scalars are affected only by the spatial distribution of tree components (i.e. the geometrical component of tree architecture). On contrast, due to stemflow, rainfall interception also depends on tree topology (i.e. the physical connections between tree components making the branching system). For all resources, the modelling approach is primarily driven by the way to represent tree architecture. Three major approaches can be distinguished (in addition to the big leaf approach which is unsuitable for tree structure-function models). Firstly, in the turbid medium approach [116], the canopy is abstracted as a "leaf gas" and geometrical structure is described in terms of tree component density functions, on an area basis (i.e. intercepting surfaces, especially the spatial distribution of leaf area density). The canopy can be described as a multi-layered medium [82], a collection of crowns modelled by geometric shapes [76] or a matrix of 3D cells [123]. In the latter case the space occupied by vegetation is divided into horizontal layers and vertical slices, the intersection of which makes cubic cells. Note that the turbid medium approach disregards tree topology. Secondly, plant architecture including both geometry and topology can be described from virtual plants, where the shape, size, location, orientation and topological links of every tree component is explicitly taken into account [54]. Thirdly, some tree structure-function models use simpler architecture descriptions, mainly based on the cumulative leaf area index in vertical and horizontal directions, for light and wind attenuation, respectively [29, 109].

\subsection{Radiation transfer}

With regard to radiation, tree components act as sinks for interception and sources in case of the emission of thermal infra red radiation. Scattering processes at the surface of the organs depends on wavelength and redistribute a fraction of intercepted radiation in space. Due to the spatial distribution of the organs in the canopy, fractional interception of direct sun light generates a bimodal (i.e. either shaded or sunlit) distribution of light within the canopy (e.g. [117]). This leads to very high variability in the light conditions encountered in canopies $[5,8$, 25] (figure 3a) although light distribution is made more uniform due to the ratio of diffuse to global incident radiation $(D / G)$, scattering and penumbra effects [102]. Temporal variability of the light regime also occurs in canopies at different time scales, i.e. due to the sun course, clouds and the effect of wind on foliage movements [115].

Many simulation models have been proposed for radiation transfer within canopies. Models deal with only interception, interception plus scattering in the solar spectrum $(0.3-3 \mu \mathrm{m})$, or interception plus scattering plus emission in the case of the thermal infrared radiation $(5-50 \mu \mathrm{m})$. Most of radiation models use the turbid medium analogy, and therefore are based on the general equation of radiation transfer (see [116]):

$$
\frac{\mathrm{d} I_{\Omega}}{\mathrm{d} L}=\frac{G_{\Omega}}{\cos \theta} \cdot I_{\Omega}+\frac{1}{\pi} \int_{4 \pi} \frac{\Gamma\left(\Omega^{\prime}, \Omega\right)}{\cos \theta} \cdot I_{\Omega^{\prime}} \cdot \mathrm{d} \Omega^{\prime} .
$$

The left member of equation (13) represents the change in photon flux $I_{\Omega}$ coming from direction $\Omega$ when crossing a small vegetation layer $\mathrm{d} L$. The first term of the right member accounts for interception according to the projected area of the vegetation components $G_{\Omega}$ in direction $\Omega$ and zenith angle $\theta$. The second term of the right member accounts for scattering: it increases $I_{\Omega}$ with radiation coming from every direction $\Omega^{\prime}$, according to the optical properties of the plant components $\Gamma\left(\Omega^{\prime}, \Omega\right)$ (i.e. the fraction of radiation coming from direction $\Omega^{\prime}$ which 
is reflected and/or transmitted in direction $\Omega$ ). Several methods have been proposed to solve the integro-differential equation (13) (see review by Myneni et al. [97]). The simplest models disregard the scattering term, and this leads to the classical exponential attenuation, i.e. Beer's law:

(a)

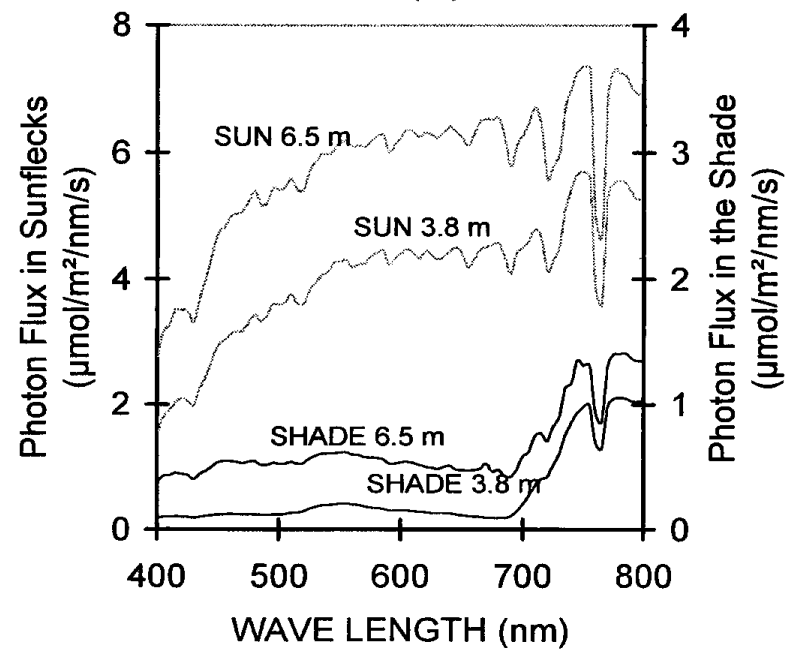

(c)

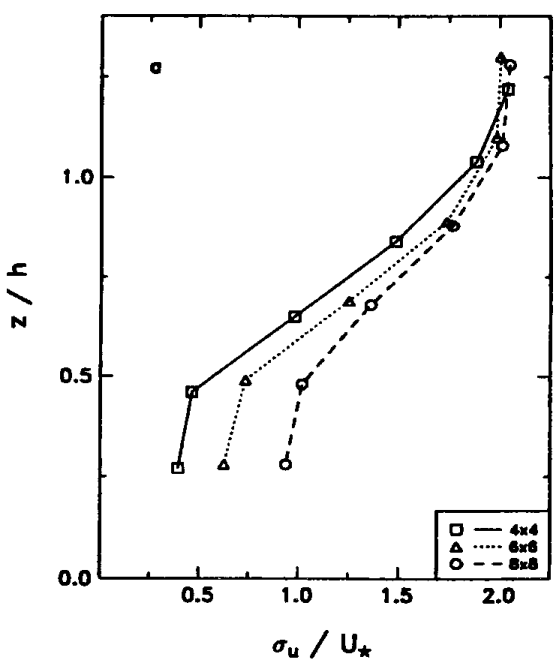

$$
I_{\Omega}=I_{\Omega}^{0} \cdot \exp \left[-\frac{G_{\Omega}}{\cos \theta} \cdot L\right]
$$

where $I_{\Omega}^{0}$ is the incident radiation coming from direction $\Omega$ and $L$ is leaf area index. Light models where tree

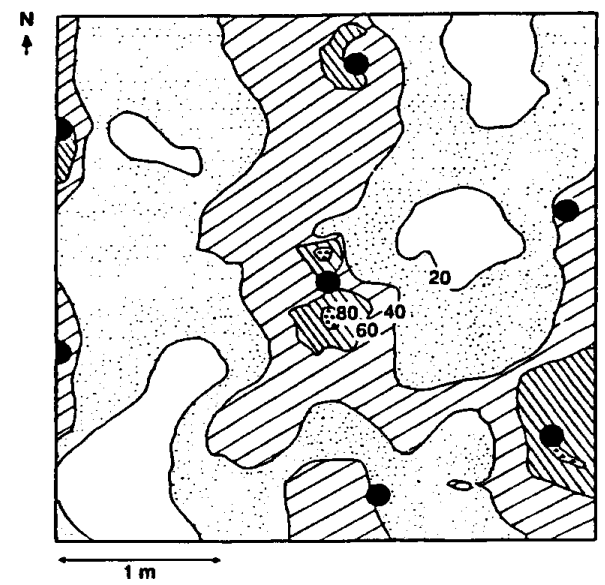

(d)

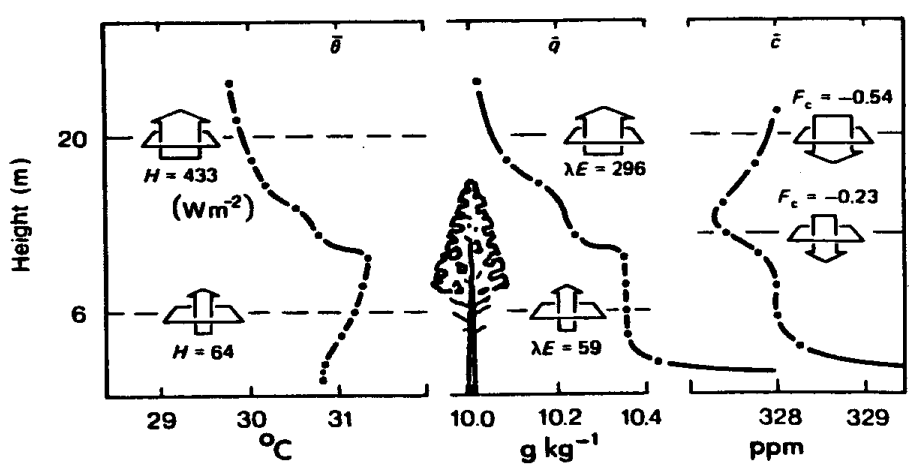

Figure 3. Illustration of some environmental changes due to tree structure and function: (a) comparison of light spectrum in sunflecks or in the shade at the top, i.e. $6.5 \mathrm{~m}$ aboveground level, and in the centre, i.e. $3.8 \mathrm{~m}$ aboveground level, of an isolated walnut tree crown (after [25]); (b) throughfall heterogeneity under Sitka spruces (from [49]); (c) mean vertical profiles of normalised standard deviations of one horizontal wind component $\left(\sigma_{/} / U^{*}\right)$ measured in plots with Sitka spruce trees spaced at intervals of c.a. 4,6 , and $8 \mathrm{~m}$ (from [56]); (d) profiles of average temperature $\theta$, mass fraction of water vapour $q$, and volume fraction of $\mathrm{CO}_{2} c$ within a forest stand, with concurrent measured fluxes of sensible heat $H\left(\mathrm{~W} \mathrm{~m}^{-2}\right)$, latent heat $\lambda E\left(\mathrm{~W} \mathrm{~m}^{-2}\right)$ and $\mathrm{CO}_{2}$ fluxes $F c\left(\mathrm{mg} \mathrm{m}^{-2} \mathrm{~s}^{-1}\right)$ (from [36]). 
crowns and/or shoots are abstracted as turbid medium geometric shapes (frustrums, ellipsoids, cylinders) have been proposed by Norman and Jarvis [99] and the Finnish group (e.g. [76, 103]). Some of these models allow grouping of foliage within shoots and of shoots within tree crowns to be taken into account. A simplified version of Norman and Jarvis' model was then used in MAESTRO [137] while Cescatti [17] proposed a flexible parameterisation allowing for a large range of crown shapes in the model FOREST. Among light models abstracting the canopy as a matrix of $3 \mathrm{D}$ cells, some deal only with the interception process (e.g. [21, 33, 139]) while others include an accurate treatment of scattering, mainly for remote sensing purposes (e.g. [52, 74, 96]). We also developed a light transfer model based on 3D cells (RIRI [122]). It was first applied to intercropping systems and allows light partitioning between vegetation components to be simulated. The RIRI model was recently used to compute light distribution within an isolated tree crown [25].

Computation of light interception (i.e. disregarding scattering) from virtual plants is easy since it only consists of projecting the vegetation components in a set of directions [20, 106, 110, 129]. Including scattering in virtual plant models can be made from ray-tracing techniques [30] or radiosity methods [19], but it is much more difficult, mainly due to the large number of radiation exchangers in a tree canopy. An intermediate solution was proposed by Dauzat et al. [31] who computed interception from virtual plants and scattering by the turbid medium analogy.

\subsection{Rainfall interception}

Rainfall interception by tree canopies involves processes similar to those involved in radiation interception. A fraction of incident rainfall reaches the soil surface through the gaps between the plant components. Intercepted rainfall may evaporate, or be redistributed by splashing, dripping and stemflow. Splashing and dripping may be regarded as "rain scattering" processes because they alter the direction and size of droplets. Studies on rainfall interception have been mostly motivated by environmental purposes [16]: water loss due to interception, erosion due to stemflow and dripping, disease survival due to wetness duration and disease dispersal due to splashing. In the context of the relations between tree structure and tree function, direct throughfall and stemflow induce spatial variability of rainfall water at the ground surface (e.g. [3, 49, 83] figure 3b) which has been correlated to the distribution of superficial fine roots [49] and soil water uptake [10]. Rainfall interception may therefore be regarded as the first step of water resource partitioning between plants, i.e. due to their individual funnelling ability (see the review by Bussière [16]).

Theoretical treatment of rainfall interception has received much less effort than other microclimatic variables. Almost all models are based on Rutter et al.'s [118], i.e. an equation for the balance of rainwater storage by the canopy $(C)$ :

$$
\frac{\mathrm{d} C}{\mathrm{~d} T}=P_{\mathrm{g}}-p \cdot P_{\mathrm{g}}-K \cdot \exp (b \cdot C)-E_{\mathrm{p}} \cdot \frac{C}{S}
$$

where $P_{\mathrm{g}}$ is incident rainfall, $p$ is the free throughfall coefficient, $E_{\mathrm{p}}$ is potential evaporation rate, $S$ is the maximum canopy storage capacity, and $K$ and $b$ are coefficients. The three last terms of right member of equation (15) account for free throughfall, drainage from the canopy (stemflow plus dripping) and evaporation loss, respectively. Model parameters have to be empirically related to canopy structure (e.g. LAI and bark content since bark largely contributes to storage capacity [60]). Rutter et al.'s model was improved by Gash [51] who refined the interception loss terms. In order to avoid the use of empirical parameters, Jiagang [68] proposed a rainfall interception model explicitly based on the turbid medium analogy. All these models were firstly aimed at estimating the interception loss at canopy level and do not deal with spatial distribution of rainfall either within the canopy or at the ground surface, although this would be of interest in the context of tree structure-function models. Simple computations of rainfall interception by virtual plants including throughfall, stemflow and dripping was proposed by Salmon [119]. Although leaf surface properties (e.g. wetness, rugosity) were not included in the model, simulated spatial patterns of rainwater on the ground were in good agreement with measurements.

\subsection{Momentum transfer}

Like radiation, momentum is absorbed by the tree components which act as passive momentum sinks, due to the drag force. However, unlike radiation, local absorption of momentum has consequences for wind characteristics at larger distances, due to momentum transport by turbulent structures. Both processes (i.e. drag force and momentum transport) result in an exponential vertical profile of the horizontal mean wind speed in closed forest canopies (e.g. $[120,131])$ and affect turbulence within the canopy (i.e. fluctuations of wind speed [71]). Turbulence within canopies is mainly dominated by coherent structures, with a spatial scale of several times the height of the canopy [24]. Such eddies are responsible for most of the exchanges between the 
canopy and the atmosphere. For example, Collineau and Brunet [24] reported time scales of $60 \mathrm{~s}$ and length scale of $120 \mathrm{~m}$ for a pine forest. Wind characteristics are also affected by the vegetation density, especially tree spacing (e.g. figure $3 c$ [56]). Heterogeneous or discontinuous canopies induce spatial variation of mean wind speed in the horizontal plane, as reported by Green et al. (1995) in case of an orchard and Daudet et al. (1999) within an isolated tree crown.

With regard to momentum absorption, all simulation models are based on the equation of momentum balance which is applied to horizontal layers or 3D cells describing both the canopy space and the space above the canopy. For the horizontal direction $x$, the equation of instantaneous momentum balance of a small fixed volume $\mathrm{d} x . \mathrm{d} y . \mathrm{d} z$ can be written (e.g. see [140])

$$
\frac{\partial \rho u}{\partial t}=\left(u \frac{\partial \rho u}{\partial x}+v \frac{\partial \rho u}{\partial y}+w \frac{\partial \rho u}{\partial z}\right)+k_{\mathrm{M}}\left(\frac{\partial^{2} \rho u}{\partial x^{2}}+\frac{\partial^{2} \rho u}{\partial y^{2}}+\frac{\partial^{2} \rho u}{\partial z^{2}}\right)-\frac{\partial p}{\partial x}
$$

where $u, v, w$ are components of wind speed in directions $x, y, z$, respectively, $p$ is air pressure, $\rho$ is air density and $k_{\mathrm{M}}$ is molecular diffusivity of momentum. Equation (16) expresses that components of momentum change are transport by the air movement in three directions $(x, y, z)$ (i.e. the 1 st term of right member), molecular diffusion due to viscosity forces (i.e. the 2 nd term) and the gradient of air pressure, (i.e. the $3 \mathrm{rd}$ term). Equations similar to (16) can be written for momentum conservation along directions $y$ and $z$, although a gravity component has to be included for the $z$ direction. Assuming the air is an incompressible fluid makes $\rho$ a constant and is a first simplification in solving equation (16). Moreover equation (16) applies to instantaneous wind speed while we are interested in mean wind speed. As proposed by Reynolds, variables $u, v, w$ are therefore separated into mean and fluctuating quantities, characterised by an overbar and prime, respectively, and equation (16) is averaged over time and space. In simple cases (horizontally homogeneous canopies, flat terrain, stationary conditions), momentum transport and the drag force due to plants are the only significant terms (Brunet, pers. comm.), so averaging of equation (16) simplifies to (e.g. [140])

$$
\frac{\partial \overline{u^{\prime} u^{\prime}}}{\partial x}+\frac{\partial \overline{u^{\prime} v^{\prime}}}{\partial y}+\frac{\partial \overline{u^{\prime} w^{\prime}}}{\partial z}+S_{\mathrm{DF}}(u)=0
$$

where $S_{\mathrm{DF}}(u)$ is momentum absorption by plant components, including both viscosity and pressure forces. Wilson and Shaw [141] proposed $S_{\mathrm{DF}}(u)$ to be modelled as:

$$
S_{\mathrm{DF}}(u)=C_{\mathrm{D}} \cdot a(x, y, z) \cdot \bar{u}^{2}
$$

where $C_{\mathrm{D}}$ is the drag coefficient $(\approx 0.2[14])$ and $a(x, y, z)$ is leaf area density. Equation (17) shows that correlation terms of wind fluctuations are a major determinant of momentum balance. However, they are unknown, so additional assumptions have to be made to relate the correlation terms to mean wind speed, i.e. the variable of interest. This process is called "equation closure". The simplest assumption (1st order closure) consists of introducing a function of turbulent diffusivity, e.g. in the 1D case

$$
\overline{u^{\prime} w^{\prime}}=K_{\mathrm{m}} \cdot \frac{\partial \bar{u}}{\partial z}
$$

Such an assumption with an adequate choice of the function $K_{\mathrm{m}}$ leads to the classical logarithmic vertical wind profile above a closed canopy (i.e. where $\overline{S_{\mathrm{DF}}(u)}=0$ ) and an exponential profile within the canopy. However, due to the weakness of 1 st order closure (e.g. see discussion by Wilson [140]), higher order schemes of equation closure have been proposed, especially in 3D wind models (e.g. [57, 143]). They need additional equations, especially the balance of turbulent kinetic energy.

Computations of wind distribution from virtual plants has never been proposed. Indeed the gain due to a fine description of tree architecture would be very low, since turbulence occurs at scales larger than that of plant organs, and because the assumptions used in the models (especially, equation closure) are weak in comparison to those associated with canopy structure [13].

Due to the complexity of momentum transfer, simpler empirical approaches have been proposed. In particular, Daudet et al. [29] related horizontal wind attenuation within the crown of an isolated tree to the cumulated leaf area computed from crown edge along the wind path.

\subsection{Scalar transfer}

The heat and gas contents of air are influenced by both tree structure and tree function. Tree structure passively affects the turbulent transfer of scalars via its action on wind characteristics, while tree function provides scalar sources or sinks, e.g. of heat due to the energy balance of the tree components, water vapour due to transpiration, $\mathrm{CO}_{2}$ in relation to photosynthesis and respiration, and trace gases emitted or absorbed by the tree foliage (e.g. isoprene [58]; $\mathrm{NO}-\mathrm{NO}_{2}-\mathrm{O}_{3}$ triad [72]). Both transport and production processes result in spatial variation of these scalars within tree canopies (e.g. figure $3 d$ [36]), especially along vertical transects in dense forest stands. 
The starting point for modelling scalar transfer is the conservation law for the mass of the scalar entity [112]. Two approaches have been proposed. In the Eulerian approach, the conservation law is applied to a small volume fixed in space

$$
\frac{\partial c}{\partial t}=-\left(u \frac{\partial u}{\partial x}+v \frac{\partial c}{\partial y}+w \frac{\partial c}{\partial z}\right)+k_{c}\left(\frac{\partial^{2} c}{\partial x^{2}}+\frac{\partial^{2} c}{\partial y^{2}}+\frac{\partial^{2} c}{\partial z^{2}}\right)
$$

where $c$ is scalar concentration and $k_{\mathrm{c}}$ the molecular diffusivity of scalar $c$. Equation (20) is similar to Equation (16) for momentum transfer: the 1st and 2nd terms of right member account for scalar transport due to air movement and molecular diffusion, respectively.

As for momentum transfer, variables are split into mean and fluctuation, and Eq. (20) is averaged over space and time

$$
\frac{\partial \bar{c}}{\partial t}=-\left(\frac{\partial \overline{u c}}{\partial x}+\frac{\partial \overline{v c}}{\partial y}+\frac{\partial \overline{w c}}{\partial z}\right)-\left(\frac{\partial \overline{u^{\prime} c^{\prime}}}{\partial x}+\frac{\partial \overline{v^{\prime} c^{\prime}}}{\partial y}+\frac{\partial \overline{w^{\prime} c^{\prime}}}{\partial z}\right)+S_{c}(x, y, z, t)
$$

where the terms of right member account for an advective flux, an eddy flux and scalar source $S$, respectively. The latter is a term of molecular diffusion occuring at solid surfaces (see [48]), i.e. due to the presence and functioning of tree components (e.g. transpiration rate for air moisture, net assimilation for $\mathrm{CO}_{2}$ ). Like momentum transfer, Equation (21) contains unknown terms of fluctuation correlation and then needs additional hypotheses for equation closure. All closure models involve a gradient-diffusion hypothesis at either first or higher order. All workers involved in turbulent transfer (e.g. $[37,48,112,140])$ agree that such unavoidable equation closure makes the Eulerian approach inappropriate within the canopy. This is because gradient-diffusion hypothesis assumes scalar transfer at local scale, while transfer is dominated by eddies of length scale comparable with canopy height.

An alternative to the Eulerian approach is the Lagrangian one, where the conservation equation is applied to a fluid particle, i.e. an infinitesimal control volume moving with the fluid

$$
\frac{\mathrm{d} c}{\mathrm{~d} t}=S(X(t), t)
$$

where $X(t)$ is the position of the particle at time $t$ and $S(x, t)$ describes the scalar source distribution. Due to the random nature of turbulence, the solution of the Lagrangian conservation equation (Eq. 22) deals with a mean value of the scalar concentration field

$$
c(x, t)=\iint P\left\langle x, t \mid x_{0}, t_{0}\right\rangle \cdot S\left(x_{0}, t_{0}\right) \mathrm{d} x_{0} \mathrm{~d} t_{0}
$$

where $P\left\langle x, t \mid x_{0}, t_{0}\right\rangle$ is the transition probability function, i.e. the conditional probability that a fluid particle lying at position $x$ at time $t$ was at position $x_{0}$ at time $t_{0}$. $P\left\langle x, t \mid x_{0}, t_{0}\right\rangle$ only depends on fluid motion, and needs to be modelled in order to evaluate $c(x, t)$ from equation (23). The model for $\mathrm{P}$ has a similar role as equation closure in the Eulerian approach [112]. An analytical model was proposed by Raupach [111] in the case of steady, homogeneous turbulence. In the case of a pine forest treated as a multilayer canopy, Ogée [101] rewrote equation (23) as a system of linear equations relating the vertical profiles of scalar concentration and source to the vertical profiles of mean wind speed and turbulence. From our knowledge, no scalar transfer model has been proposed in the case of complex 3D canopies. Authors however agree that Lagrangian theory only needs a rather crude model for the wind field [37, 140]. Further details on both the Eulerian and the Lagrangian approach for scalar transfer within canopies can be found in the excellent reviews proposed by Raupach [112], Denmead and Bradley [37] and Wilson [140].

\section{CURRENT REPRESENTATIONS OF TREE FOLIAGE/ENVIRONMENT INTERACTIONS IN FUNCTIONAL-STRUCTURAL TREE MODELS}

Table I gives the characteristics of static models integrating interactions between tree structure, tree function and the aboveground environment. Models were sampled so that they represent the range of modelling approaches proposed in the literature. In the context of structural-functional tree models, models quoted in table I were also chosen so that they explicitly simulate photosynthesis and/or transpiration at a intra-canopy scale, in order to predict carbon and/or water fluxes by scaling from the leaf to the tree or the canopy (e.g. [82, 134]), or to describe the spatial variations at an intracanopy scale (e.g. [31, 123]). Thus all quoted models explicitly include radiation transfer, leaf photosynthesis and/or energy balance calculations.

Modelling radiation transfer uses either the turbid medium approach applied to geometric shapes (e.g. [134]), multilayer (1D model, e.g. [82]), 2D (e.g. [23]) and 3D (e.g. [123]) tree canopies, or virtual plants described at leaf scale (e.g. [31]). Transpiration is computed from the energy balance, either analytically (i.e. the Penman-Monteith equation, e.g. [137]) or numerically solved (e.g. [123]). Leaf conductance is generally 
Table I. Representation of the interactions between tree structure/function and the aboveground environment in eight static functional-structural tree models (EB: energy balance; Emp. empirical; P-M: Penman-Monteith; TM: turbid medium).

\begin{tabular}{|c|c|c|c|c|c|c|c|c|}
\hline Model & Radiation & Transpiration & $\begin{array}{c}\text { Stomatal } \\
\text { conductance }\end{array}$ & Photosynthesis & Wind & $\begin{array}{l}\text { Scalar } \\
\text { transfer }\end{array}$ & $\begin{array}{c}\text { Leaf } \\
\text { nitrogen }\end{array}$ & Drought \\
\hline $\begin{array}{l}\text { Cohen et al., } \\
1987\end{array}$ & $\begin{array}{c}\mathrm{TM} \\
\text { 2D cells }\end{array}$ & EB & Jarvis, 1976 & Emp. & Emp. & $1 \mathrm{D}$ & - & $-\quad-$ \\
\hline $\begin{array}{l}\text { Dauzat et al. } \\
1999\end{array}$ & $\begin{array}{l}\text { Virtual } \\
\text { Plants }\end{array}$ & $\begin{array}{c}\mathrm{EB} \\
\text { Iterative }\end{array}$ & Jarvis, 1976 & - & $\begin{array}{l}\text { Emp. } \\
\text { 1D }\end{array}$ & - & - & $\begin{array}{c}\text { Coupling } \\
\text { with sapflow }\end{array}$ \\
\hline $\begin{array}{l}\text { Leuning et al. } \\
1995\end{array}$ & $\begin{array}{c}\text { TM } \\
\text { Multilayer }\end{array}$ & $\begin{array}{l}\text { EB } \\
\text { P-M }\end{array}$ & $\begin{array}{c}\text { Modified } \\
\text { Ball et al. } \\
\text { (1987) }\end{array}$ & $\begin{array}{c}\text { Farquhar et al., } \\
1980\end{array}$ & $\begin{array}{l}\text { Emp. } \\
\text { 1D }\end{array}$ & - & $\begin{array}{l}\text { Emp. } \\
\text { 1D }\end{array}$ & - \\
\hline $\begin{array}{l}\text { Pearcy and } \\
\text { Yang, } 1996\end{array}$ & $\begin{array}{l}\text { Virtual } \\
\text { Plants }\end{array}$ & - & - & Emp. & - & - & - & - \\
\hline $\begin{array}{l}\text { Sinoquet } \\
\text { et al., } 2000\end{array}$ & $\begin{array}{c}\mathrm{TM} \\
\text { 3D cells }\end{array}$ & $\begin{array}{c}\mathrm{EB} \\
\text { Iterative }\end{array}$ & Jarvis, 1976 & $\begin{array}{l}\text { Farquhar } \\
\text { et al., } 1980\end{array}$ & $\begin{array}{l}\text { Emp. } \\
\text { 3D }\end{array}$ & - & $\begin{array}{l}\text { Emp. } \\
\text { 3D }\end{array}$ & - \\
\hline $\begin{array}{l}\text { Thorpe et al., } \\
1978\end{array}$ & $\begin{array}{c}\text { TM } \\
\text { Tree shapes }\end{array}$ & $\begin{array}{c}\mathrm{EB} \\
\text { Iterative }\end{array}$ & $f(\mathrm{PAR})$ & Emp. & - & - & - & - \\
\hline $\begin{array}{l}\text { Wang and } \\
\text { Jarvis, } 1990\end{array}$ & $\begin{array}{c}\text { TM } \\
\text { Tree shapes }\end{array}$ & $\begin{array}{l}\text { EB } \\
\text { P-M }\end{array}$ & Jarvis, 1976 & $\begin{array}{c}\text { Emp. or } \\
\text { Farquhar et al. }\end{array}$ & Emp.? & - & - & - \\
\hline
\end{tabular}

modelled by using the Jarvis model [66], although a modified version of Ball et al.'s approach is used by Leuning et al. [82]. All models include the biochemical leaf photosynthesis model proposed by Farquhar et al. [45], except the oldest ones (e.g. [23, 134]) where an empirical assimilation $v s$. irradiance relationship is used.

Models quoted in table I scarcely treat momentum and scalar transfer. On one hand, when simulated, wind distribution is computed as a vertical profile, i.e. the approximate exponential attenuation assumed in horizontally homogeneous canopies (e.g. [31, 82]). In Sinoquet et al.'s model [123], the horizontal attenuation of wind speed in an isolated crown is approximated by an empirical relationship (see [29]). On the other hand, scalar transfer has never been included in structuralfunctional tree models. This is because quoted models simulate fluxes at the interface between tree foliage and the atmosphere from a tree perspective: $\mathrm{CO}_{2}$ and $\mathrm{H}_{2} \mathrm{O}$ fluxes are viewed as photosynthesis and transpiration processes, respectively, rather than scalar sources for the atmosphere. As mentioned by Leuning et al. [82], integrating Lagrangian transfer within tree models would be a complex task (see above), and would need taking into account the contribution of the soil (i.e. respiration and evaporation). Moreover, in a number of cases, air characteristics (i.e. wind, temperature and humidity) do not show large spatial variations, and/or these spatial variations do not have large effects on $\mathrm{CO}_{2}$ and $\mathrm{H}_{2} \mathrm{O}$ fluxes between the tree and the atmosphere (this is particularly true for isolated trees, see [29]). Disregarding the effect of tree function on air characteristics however prevents from simulating tree function in contrasting growing conditions (e.g. isolated $v s$. densely planted trees), except if microclimate variables are measured within each canopy.

Some models take into account the spatial distribution of physiological parameters, especially photosynthetic leaf properties which can be related to leaf nitrogen content (see above). In a multilayer canopy model [82], spatial distribution of leaf $N$ was described by an exponential function of the cumulative downward leaf area index, i.e. an implicit way to relate leaf nitrogen content to leaf irradiance. In the 3D model proposed by Sinoquet et al. [123], the spatial distribution of leaf $N$ was simulated from leaf irradiance integrated on 7 days (see [78]). Such relationships are empirical and do not derive from a mechanistic model of leaf plasticity to the light environment. In the other models, nitrogen is implicitly assumed to be uniformly distributed. This can lead to significant underestimation of assimilation rates $(\approx 10 \%$, [62]).

In most models quoted in table $I$, drought effects are not explicitly accounted for, but they could be included by adding the effect of soil or leaf water potential in the stomatal conductance model of Jarvis [66]. This requires to use soil and/or leaf water potential as an additional input variable. Dauzat et al. [31] coupled their transpiration model with internal water fluxes, i.e. in the tree topology, in order to simulate the distribution of water 
potential within the tree. Despite the increasing model complexity, such a way may be regarded as an useful integration exercise in the context of structural-functional tree models.

Table II gives features of tree-environment interactions treatment in a range of structural-functional models of tree dynamics. All models include submodels of light interception (except [34]) and photosynthate production, because they assume that carbon balance is the key determinant of tree growth and architecture dynamics. Submodels of light interception may range from simple to complex: LIGNUM [109] uses a modified Beer's law where PAR attenuation is computed from the biomass above each location. In contrast, ECOPHYS [113] includes light calculations based on virtual plants. This was made possible because ECOPHYS deals with young trees, i.e. with a limited number of leaves. In the other models, 3D computations of leaf or shoot irradiance are based on the turbid medium analogy. Models quoted in table II also apply different approaches to compute photosynthate production. In the simplest approaches, photosynthate production is calculated from a constant light use efficiency (LUE) (Eq. 10b) [73, 129] or from the leaf specific activity approach (Eq. 10a) [109]. De Reffye et al. [34] estimate local carbon gains from local transpiration by assuming a constant water use efficiency (WUE) within the tree. In contrast, the most sophisticated treatment of photosynthesis corresponds to the biochemical model of Farquhar et al. [45] (e.g. [4]).

Despite the fact that they are designed to simulate tree growth and architecture dynamics over long periods (generally several years), most models in table II do not deal with delayed tree responses such as light acclimation: the only exception is the model SIMWAL [4] that accounts for light acclimation of leaf photosynthetic properties (via empirical relationships between leaf nitrogen and leaf irradiance). Similarly no model explicitly accounts for stomatal conductance, because they mostly disregard plant water relations. Balandier et al. [4] however used an empirical relationship (Eq. 4) to implicitly account for the effect of stomatal aperture on internal $\mathrm{CO}_{2}$ concentration $C_{\mathrm{i}}$. Because transpiration is computed from internal water fluxes, De Reffye et al. [34] did not take into account stomata in their model. Finally, no model includes tree-driven environmental changes, except the effect of tree structure on light interception.

Table II. Treatment of some instantaneous and delayed tree responses to aboveground environmental variables, and representation of some environmental changes due to tree structure and function in six dynamic structural-functional tree models.

\begin{tabular}{|c|c|c|c|c|c|}
\hline & $\begin{array}{l}\text { ECOPHYS } \\
\text { (Rauscher } \\
\text { et al., 1990) }\end{array}$ & $\begin{array}{l}\text { WALSIM } \\
\text { (Balandier } \\
\text { et al., 2000) }\end{array}$ & $\begin{array}{l}\text { LIGNUM } \\
\text { (Perttunen } \\
\text { et al., 1996) }\end{array}$ & $\begin{array}{l}\text { Takenaka (1994b) } \\
\text { Kellomaki (1995) }\end{array}$ & $\begin{array}{l}\text { De Reffye } \\
\text { et al. (1997) }\end{array}$ \\
\hline \multicolumn{6}{|l|}{ Instantaneous tree responses } \\
\hline *stomatal function & None & $C_{\mathrm{i}} / C_{\mathrm{a}}=f(\mathrm{PAR})$ & None & None & $?$ \\
\hline *photosynthate production & $\begin{array}{l}\text { Rectangular } \\
\text { hyperbola } \\
A=f(\text { PAR } \\
T, \text { age })\end{array}$ & $\begin{array}{c}\text { Farquhar } \\
\text { model } \\
A=f(\mathrm{PAR} \\
\left.T, N, C_{\mathrm{a}}\right)\end{array}$ & $\begin{array}{c}\text { Annual } \\
\text { productivity } \\
P=f(\text { PAR })\end{array}$ & $\begin{array}{l}\text { Constant } \\
\text { LUE }\end{array}$ & $\begin{array}{l}\text { Constant } \\
\text { WUE }\end{array}$ \\
\hline \multicolumn{6}{|l|}{ Delayed tree responses } \\
\hline $\begin{array}{l}\text { *light acclimation of } \\
\text { photosynthetic capacities }\end{array}$ & None & $\begin{array}{l}N=f(\text { light } \\
\text { regime })\end{array}$ & None & None & None \\
\hline $\begin{array}{l}\text { *light acclimation of shoot } \\
\text { morphology (STAR...) } \\
\text { except shoot length and volume }\end{array}$ & None & None & None & None & None \\
\hline \multicolumn{6}{|l|}{ Tree-driven environmental changes } \\
\hline *wind speed & No & No & No & No & No \\
\hline *air VPD & No & No & No & No & No \\
\hline *light quantity & $\begin{array}{l}\text { Interception of } \\
\text { direct and diffuse } \\
\text { by each leaf }\end{array}$ & $\begin{array}{l}\text { Interception of } \\
\text { direct and diffuse } \\
\text { by each leaf }\end{array}$ & $\begin{array}{c}f \text { (biomass } \\
\text { above each } \\
\text { location) }\end{array}$ & $\begin{array}{l}\text { Beer's law } \\
\text { for leaf clusters }\end{array}$ & No \\
\hline *light quality & No & No & No & No & No \\
\hline
\end{tabular}




\section{THE NEED OF SIMPLE, REALISTIC FORMULATIONS FOR ABOVEGROUND INTERACTIONS IN FUNCTIONAL- STRUCTURAL TREE MODELS}

Process representations used in detailed models representing the tree-environment interactions (see table I) can be too complex and inadequate for simulations over long periods required by models predicting tree architecture dynamics for instance. However, the detailed models mostly static models - can be used to test simplifying assumptions used in dynamic tree models (see table II) such as (i) the constancy of light use efficiency (LUE), i.e. carbon assimilation rate per unit of absorbed PAR is approximately constant in absence of water stress, (ii) the constancy of water use efficiency (WUE), i.e. carbon assimilation rate per unit of transpired water is approximately constant, or (iii) the optimisation of leaf nitrogen allocation in the foliage with respect to carbon acquisition.

Here, simulations performed with the RATP model were used to test the first two assumptions. The model was applied to an isolated, 20-year-old walnut tree crown. RATP has already been parameterised and tested for this canopy [123]. In the reference run, the daily net assimilation and transpiration rates were computed at the $3 \mathrm{D}$ cell scale (i.e. $0.5 \times 0.5 \times 0.5 \mathrm{~m}$ ). This allowed quantification of the spatial heterogeneity of both LUE and WUE within the tree crown. In a second run, carbon gain was not computed by the Farquhar photosynthesis model (i.e. as used in the reference run), but assuming a constant LUE. In a third run, carbon gain was computed assuming a constant WUE. Constant LUE and WUE used in the second and third runs were computed as the ratio of total carbon gain computed at tree scale in the reference run to total absorbed PAR and transpired water, respectively.

\subsection{Testing the constant LUE and constant WUE hypotheses}

The light use efficiency simulated by the RATP model at the 3D cell scale was roughly constant within the tree crown (figure 4a). Light use efficiency only slightly decreased with increasing daily leaf irradiance (from 0.45 to $0.35 \mathrm{gC} \mathrm{mol} \mathrm{APAR}^{-1}$ ). Thus, using a single value for LUE at the $3 \mathrm{D}$ cell scale led to similar values of local carbon gains than computing leaf photosynthetic rates by the Farquhar model (figure $4 b$ ).

In contrast, the spatial variations of the water use efficiency computed by the RATP model at the $3 \mathrm{D}$ cell scale were important within the tree crown (figure 5a). Water use efficiency increased from $2.1 \mathrm{gC} \mathrm{kgH}_{2} \mathrm{O}^{-1}$ water
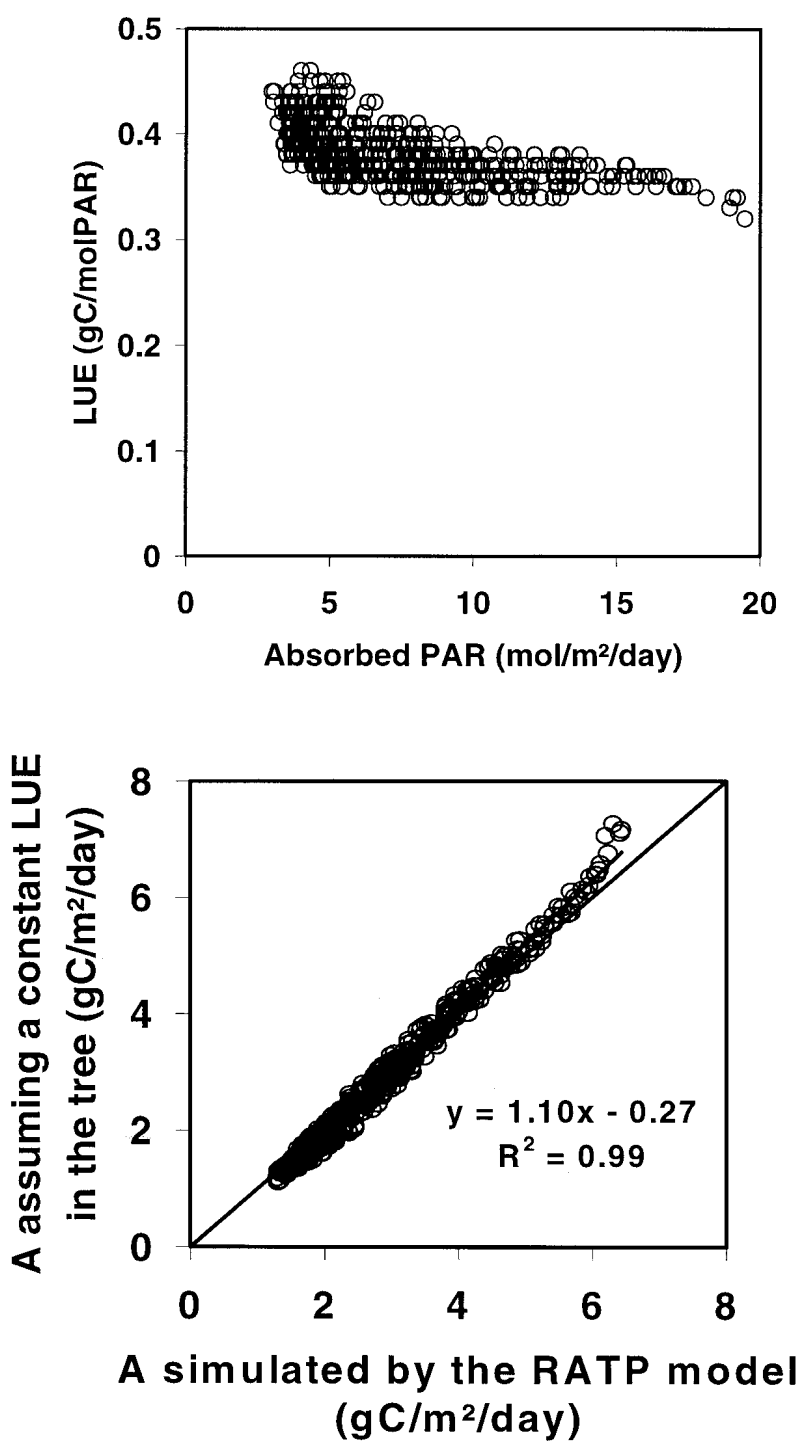

Figure 4. (a) spatial variations of the daily light use efficiency LUE as a function of daily leaf irradiance PAR within an individual walnut tree crown, both simulated by the RATP model, and (b) comparison of the daily, local photosynthetic carbon gains simulated by the RATP model (i.e. using the Farquhar photosynthesis model) or assuming a constant light use efficiency.

transpired for the shade leaves at the centre of the tree crown, up to $4.5 \mathrm{gC} \mathrm{kgH}_{2} \mathrm{O}^{-1}$ water transpired for the sun leaves at the edge of the crown. Because of this strong variability, using a single value for WUE significantly overestimated carbon gains by shade leaves and underestimated carbon gains by sun leaves (figure $5 b$ ). 

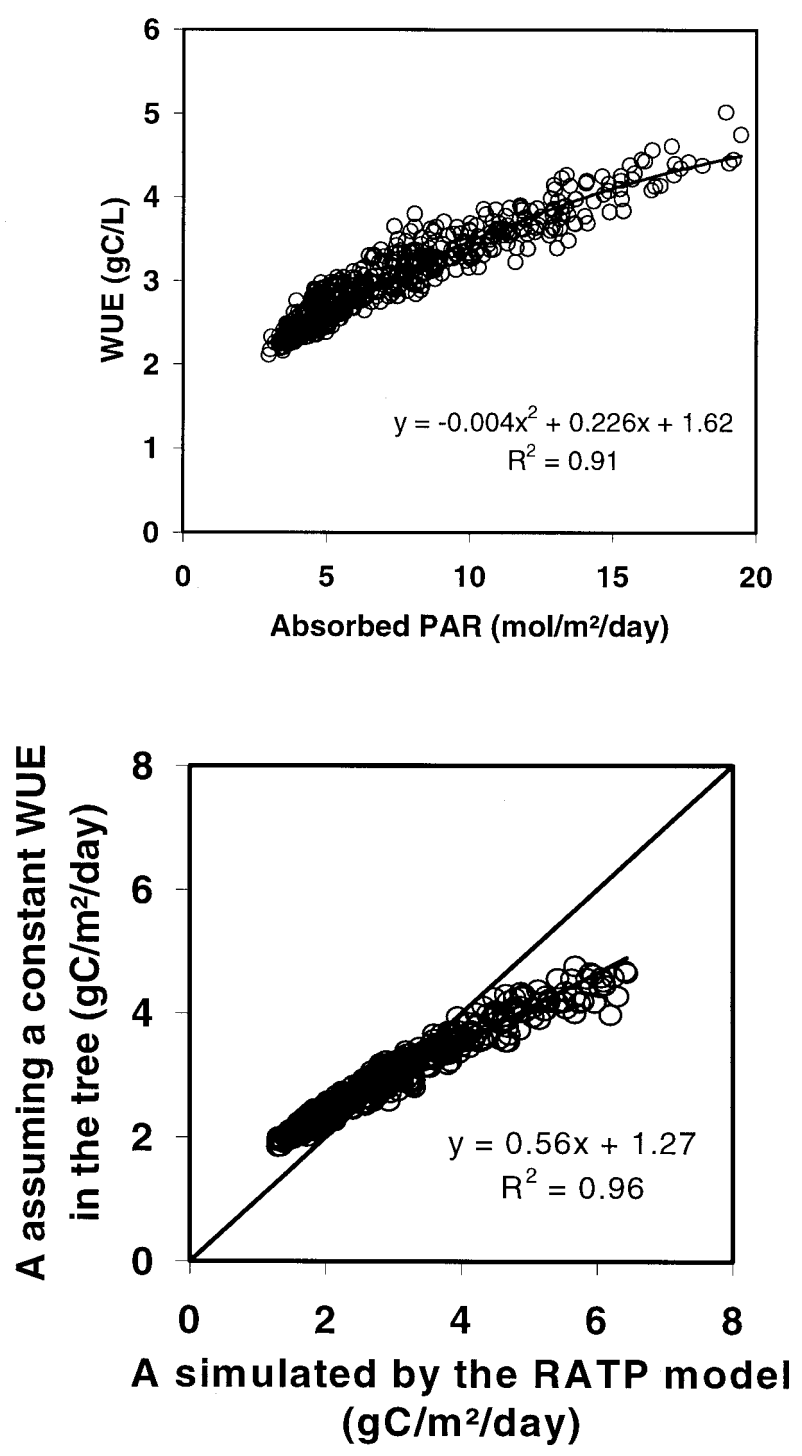

Figure 5. (a) spatial variations of the daily water use efficiency WUE as a function of daily leaf irradiance PAR within an individual walnut tree crown, both simulated by the RATP model, and (b) comparison of the daily, local photosynthetic carbon gains simulated by the RATP model (i.e. using the Farquhar photosynthesis model) or assuming a constant water use efficiency.

\subsection{Implications for the representation of local carbon gains in functional-structural tree models}

Local photosynthetic rates largely determine local shoot growth and the development and growth of organs such as flower buds and fruits [26, 32, 59]. For this rea-

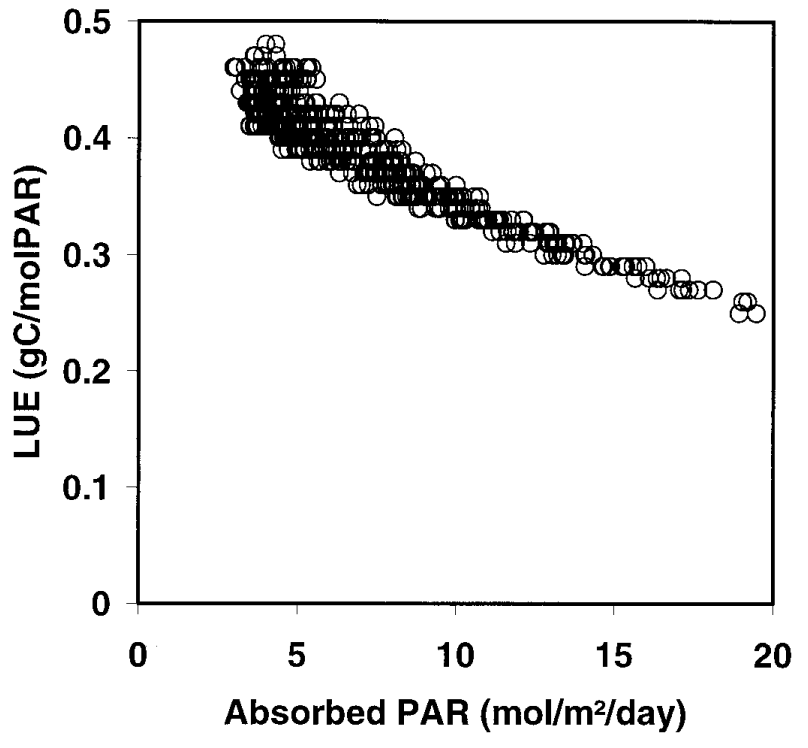

Figure 6. spatial variations of the daily light use efficiency LUE as a function of daily leaf irradiance PAR within an individual walnut tree crown, simulated as in Figure 4 but assuming a uniform distribution of leaf nitrogen within the canopy.

son, carbon-based models simulating fruit growth [80] must accurately represent individual shoot or leaf carbon gain. Similarly, tree structural growth models sometimes need to represent the heterogeneity of carbon sources within the tree crown according to the allocation scheme used (see [77]). However, the simulation results presented above showed that, according to model objectives, a detailed representation of leaf photosynthetic rates is not necessarily needed in functional-structural tree models. For instance, using a constant LUE is adequate for simulating local carbon gains within the walnut tree crown studied. The constancy of the daily light use efficiency within the tree crown resulted from the linear relationships observed in the field between the amount of nitrogen per unit leaf area, leaf photosynthetic capacities, and local leaf irradiance [78, 79]. Indeed, assuming a uniform distribution of leaf nitrogen when simulating LUE distribution within the walnut tree canopy resulted in a strong decrease of LUE with increasing time-integrated leaf irradiance (figure 6). This result is consistent with the conclusion of Dewar et al. [39] drawn from a biochemically-based model. From a practical point of view, provided that the LUE value is known, this approach is adequate for simulating tree architecture dynamics over a long time period under a given environment (e.g. a given nutrient availability and atmospheric composition). Such an approach has already been used in several functionalstructural tree models [73, 129], assuming autonomy of 
branches with respect to their carbon balance [126]. However, prescribing the LUE value implies first either to measure it or to compute it from a detailed simulation model representing explicitly leaf or shoot photosynthesis.

In contrast to LUE, WUE is not a conservative variable within vegetation canopies. Thus, using a constant WUE to compute local carbon gains from simulated local water losses [34] is not straightforward and can lead to systematic biases (figure $5 b$ ).

\section{CONCLUSION}

This overview shows that both (i) a good knowledge of processes involved in the interactions between trees and the aboveground environment and (ii) a range of modelling approaches to simulate these interactions are presently available for functional-structural tree models. This is especially the case for physical processes like radiation interception and energy balance, and biological processes like photosynthesis where the complex biochemistry has been summarised in the relatively simple model of Farquhar et al. [45]. Although much attention has been paid to other complex physical processes like momentum and scalar transfer, associated models remain complex and difficult to include in functional-structural tree models. Moreover the gain due to such inclusion in terms of model improvement is questionable. With regard to biological processes other than photosynthesis, available models are mostly empirical. This is especially the case of the stomatal conductance and the foliage acclimation to the environmental variables. A research effort is therefore needed to derive simple, general formulations of tree responses, as proposed by Dewar et al. [39] for leaf acclimation to light for instance.

An important question is to determine which knowledge and/or modelling approach should be incorporated into structural-functional tree models for given model objectives. Detailed models should be used in order to (i) assess the weight of basic processes on tree function (e.g. the potential effects of the interactions between tree function and scalar concentration within the canopy), (ii) evaluate strategies of tree function (e.g. optimisation of resource capture at the whole tree scale) and make the bridge between teleonomic and process-based models (e.g. effect of leaf nitrogen distribution on tree carbon gain, [62]), or (iii) to test simplifying assumptions and derive summary models (e.g. as illustrated in the previous section). Summary models should be further used for decision making, where the purpose is rather to obtain reasonably good predictions at the stand or tree scale (e.g. $\mathrm{CO}_{2}$ and $\mathrm{H}_{2} \mathrm{O}$ fluxes, biomass and harvest produc- tion, tree height and diameter distribution, tree architecture). Given the number of models available in the literature, model comparison (i.e. between static models, and between static and dynamic models, see tables $I$ and II) and improved communication between modellers are needed to address these questions.

Acknowledgements: The authors are grateful to Y. Brunet (INRA-Bioclimatologie, Bordeaux) for helpful suggestions on momentum and scalar transfer, and Belinda Medlyn (INRA-Forêts, Bordeaux) for valuable comments on a previous version of the manuscript.

\section{REFERENCES}

[1] Aphalo P.J., Jarvis P.G., Do stomata respond to relative humidity?, Plant Cell Env. 14 (1991) 127-132.

[2] Aphalo P.J., Jarvis P.G., An analysis of Ball's empirical model of stomatal conductance, Ann. Bot. 72 (1993) 321-327.

[3] Aussenac G., Action du couvert forestier sur la distribution au sol des précipitations, Ann. Sci. For. 27 (1970) 383399.

[4] Balandier P., Lacointe A., Le Roux X., Sinoquet H., Cruiziat P., Le Dizès S., SIMWAL: a structural-functional model simulating single walnut tree growth in response to climate and pruning, Ann. For. Sci. 57 (2000) 571-585.

[5] Baldocchi D.D., Hutchison B.A., Matt D.R., McMillen R.T., Seasonal variation in the statistics of photosynthetically active radiation penetration in an oak-hickory forest, Agric. For. Meteorol. 36 (1986) 343-361.

[6] Ball J.T., Woodrow I.E., Berry J.A., A model predicting stomatal conductance and its contribution to the control of photosynthesis under different environmental conditions. in: Biggins J. (Ed.) Progress in photosynthesis research, Martinus Nijhoff, Dordrecht, 1987, pp. 221-224.

[7] Bauer H., Thoni W., Photosynthetic light acclimation in fully developed leaves of the juvenile and adult life phases of Hedera helix, Physiol. Plant. 73 (1988) 31-37.

[8] Becker P., Smith A.P., Spatial autocorrelation of solar radiation in a tropical moist forest understory, Agric. For. Meteorol. 52 (1990) 373-379.

[9] Berryman C.A., Eamus D., Duff G.A., Stomatal responses to a range of variables in two tropical tree species grown with $\mathrm{CO}_{2}$ enrichment, J. Exp. Bot. 45 (1994) 539-546.

[10] Bouten W., Heimovaara T.J., Tiktak A., Spatial patterns of throughfall and soil water dynamics in a Douglas fir stand, Water Resource Res. 28 (1992) 3227-3233.

[11] Brooks J.R., Hinckley T.M., Sprugel D.G., Acclimation responses of mature Abies amabilis sun foliage to shading, Oecologia. 100 (1994) 316-324.

[12] Brooks J.R., Sprugel D.G., Hinckley T.M., The effects of light acclimation during and after foliage expansion on photosynthesis of Abies amabilis foliage within the canopy, Oecologia 107 (1996) 21-32. 
[13] Brunet Y., Modélisation architecturale et transferts turbulents, in: Andrieu B. (Ed.) Modélisation Architecturale, Actes du Séminaire, Paris, 10-12 March 1997, INRABioclimatologie, Paris, 1997, pp. 231-233.

[14] Brunet Y., Finnigan J.J., Raupach M.R., A wind tunnel study of air flow in waving wheat: single-point velocity statistics, Bound. Layer Meteorol. 70 (1994) 95-132.

[15] Bunce J.A., Does transpiration control stomatal responses to water vapour pressure deficit?, Plant Cell Env. 19 (1996) 131-135.

[16] Bussière F., Rainfall interception and subsequent interaction between vegetation and liquid surface water: a review, European J. Agron. (1999) in press.

[17] Cescatti A., Modelling the radiative transfer in discontinuous canopies of asymmetric crowns. I. Model structure and algorithms, Ecol. Model. 101 (1997) 263-274.

[18] Chazdon R.L., Pearcy R.W., Photosynthetic responses to light variation in rain forest species. I. Induction under constant and fluctuating light conditions, Oecologia 69 (1986) 517-523.

[19] Chelle M., Développement d'un modèle de radiosité mixte pour simuler la distribution du rayonnement dans les couverts végétaux, Ph.D. Thesis, University of Rennes I, 1997.

[20] Chen S.G., Impens I., Ceulemans R., Kockelbergh F., Measurement of gap fraction of fractal generated canopies using digitalized image analysis, Agric. For. Meteorol. 65 (1993) 245-259.

[21] Chen S.G., Shao B.Y., Impens I., Ceulemans R., Effects of plant canopoy structure on light interception and photosynthesis, J. Quant. Spectrosc. Radiat. Transfer 52 (1994) 115-123.

[22] Chow W.S., Anderson J.M., Photosynthetic responses of Pisum sativum to an increase in irradiance during growth. I. Photosynthetic activities, Aust. J. Plant Physiol. 14 (1987) 1-8.

[23] Cohen S., Fuchs M., Moreshet S., Cohen Y., The distribution of leaf area, radiation, photosynthesis and transpiration in a shamouti orange hedgerow orchard. Part II: Photosynthesis, transpiration, and the effect of row shape and direction, Agric. For. Meteorol. 40 (1987) 145-162.

[24] Collineau S, Brunet Y., Detection of turbulent coherent motions in a forest canopy. Part II: time scales and conditional analysis, Bound. Layer Meteorol. 66 (1993) 49-73.

[25] Combes D., Sinoquet H., Varlet-Grancher C., Preliminary measurement and simulation of the spatial distribution of the Morphogenetically Active Radiation (MAR) within an isolated tree canopy, Ann. For. Sci. 57 (2000) 497-511.

[26] Corelli Grappadelli C., Lakso A.N., Flore J.A., Early season patterns of carbonhydrate partitioning in exposed and shaded apple branches, J. Amer. Soc. Hort. Sci. 119 (1994) 596-603.

[27] Correia M.J., Pereira J.S., The control of leaf conductance of white lupin by xylem ABA concentration decreases with the severity of water deficits, J. Exp. Bot. 46 (1995) 101110 .

[28] Cowan I., Farquhar G.D., Stomatal function in relation to leaf metabolism and environment. Integration of activity in the higher plant, Soc. Exp. Biol. Symp., Vol. 31. Cambridge University Press, New York, 1977, pp. 471-505.

[29] Daudet F-A., Le Roux X., Sinoquet H., Adam B., Wind speed and leaf boundary layer conductance variations within tree crown: consequences on leaf-to-atmosphere coupling and tree functions, Agric. For. Meteorol. 97 (1999) 171-185.

[30] Dauzat J., Hautecoeur O., Simulation des transferts radiatifs sur maquettes informatiques de couverts végétaux, in: Physical measurements and signatures in remote sensing, Proc. 5th Int. Coll. ESA, ESA, Frascatti, Italy, 1991, pp. 415-418.

[31] Dauzat J., Rapidel B., Berger A., Simulation of leaf transpiration and sap flow in virtual plants: description of the model and application to a coffea plantation in Costa Rica, Agric. For. Meteorol. (1999) in press.

[32] Davis J.T., Sparks D., Assimilation and translocation patterns of carbon-14 in the shoot of fruiting pecan trees, Carya illinoensis Koch, J. Amer. Soc. Sci. 99 (1974) 468-480.

[33] De Castro F., Fetcher N., Three dimensional model of the interception of light by a canopy, Agric. For. Meteorol. 90 (1998) 215-233.

[34] De Reffye P., Fourcaud T., Blaise F., Barthélémy D., Houllier F., A functional model of tree growth and tree architecture, Silva Fenn. 31 (1997) 297-311.

[35] DeJong T.M., Doyle J.F., Seasonal relationships between leaf nitrogen content (photosynthetic capacity) and leaf canopy light exposure in peach (Prunus persica), Plant Cell Env. 8 (1985) 701-706.

[36] Denmead O.T., Bradley E.F., Flux-gradient relationships in a forest canopy, in: Hutchison B.A., Hicks B.B. (Eds.), The forest-atmosphere interaction, D. Reidel, Dordrecht, The Netherlands, 1985, pp. 421-442.

[37] Denmead O.T., Bradley E.F., On scalar transport in plant canopies, Irrig. Sci. 8 (1987) 131-149.

[38] Dewar R.C., Interpretation of an empirical model for stomatal conductance in terms of guard cell function, Plant Cell Env. 18 (1995) 365-372.

[39] Dewar R.C., Medlyn B.E., McMurtrie R.E., A mechanistic analysis of light and carbon use efficiencies, Plant Cell Env. 21 (1998) 573-588.

[40] Dixon R.K., Brown S., Houghton R.A., Solomon A.M., Trexler M.C., Wisniewski J., Carbon pools and flux of global forest ecosystems, Science 263 (1994) 185-190.

[41] Ellsworth D.S., Reich P.B., Canopy structure and vertical patterns of photosynthesis and related leaf traits in a deciduous forest, Oecologia 96 (1993) 169-178.

[42] Eschrich W., Burchardt R., Essiamah S., The induction of sun and shade leaves of the European beech (Fagus sylvatica L.): anatomical studies, Trees 3 (1989) 1-10.

[43] Evans J.R., Photosynthetic acclimation and nitrogen partitioning within a lucerne canopy. I. Canopy characteristics, Aust. J. Plant Physiol. 20 (1993) 55-67.

[44] Farquhar G.D., Feedforward responses of stomata to humidity, Aust. J. Plant Physiol. 5 (1978) 787-800.

[45] Farquhar G.D., von Caemmerer S., Berry J.A., A biochemical model of photosynthetic $\mathrm{CO}_{2}$ assimilation in leaves of $\mathrm{C}_{3}$ species, Planta 149 (1980) 78-90. 
[46] Ferrar P.J., Osmond C.B., Nitrogen supply as a factor influencing photoinhibition and photosynthetic acclimation after transfer of shade-grown Solanum dulcamara to bright light, Planta 168 (1986) 563-570.

[47] Field C., Allocating leaf nitrogen for the maximization of carbon gain: leaf age as a control on the allocation program, Oecologia 56 (1983) 341-347.

[48] Finnigan J.J., Turbulent transport in flexible plant canopies, in: Hutchison B.A., Hicks B.B. (Eds.), The forestatmosphere interaction, D. Reidel, Dordrecht, The Netherlands, 1985, pp. 443-480.

[49] Ford E.D., Deans J.D., The effect of canopy structure on stemflow, throughfall and interception loss in young Sitka Spruce plantation, J. Appl. Ecol. 15 (1978) 905-917.

[50] Freer-Smith P.H., Broadmeadow M.S., The uptake of particulates by urban woodland, Environ. Pollution 95 (1997) 27-35.

[51] Gash J.H.C., An analytical model of rainfall interception by forets, Quart. J. R. Meteorol. Soc. 105 (1979) 43-55.

[52] Gastellu-Etchegorry J.P., Demarez V., Pinel V., Zagolski F., Modeling radiative transfer in heterogeneous 3-D vegetation canopies, Remote Sens. Environ. 58 (1996) 131156.

[53] Godin C., Caraglio Y., A multiscale model of plant topological structure, J. Theor. Biol. 191 (1998) 1-46.

[54] Godin C., Costes E., Sinoquet H., A method for describing plant architecture which integrates topology and geometry, Ann. Bot. 84 (1999) 343-357.

[55] Grantz D., Plant response to atmospheric humidity, Plant Cell Env. 13 (1990) 667-679.

[56] Green S.R., Grace J., Hutchings N.J., Observations of turbulent air flow in three stands of widely spaced Sitka spruce, Agric. For. Meteorol. 74 (1995) 205-225.

[57] Gross G., A numerical study of the air flow within and around a single tree, Boundary-Layer Meteorol. 40 (1987) 311327.

[58] Guenther A., Greenberg J., Harley P., Helmig D., Klinger L., Vierling L., Zimmerman P., Geron C., 1996b, Leaf, branch, stand and landscape scale measurements of volatile organic compounds fluxes from U.S. woodlands, Tree Physiol. $16,17-24$.

[59] Hansen P., ${ }^{14} \mathrm{C}$-studies on apple trees. I. The effect of the fruit on the translocation and distribution of photosynthesis, Physiol. Plant. 20 (1967) 382-391.

[60] Herwitz S.R., Interception storage capacity of tropical rainforest canopy trees, J. Hydrol. 77 (1985) 237-252.

[61] Hikosaka K., Murakami A., Hirose T., Balancing carboxylation and regeneration of ribulose-1,5-bisphosphate in leaf photosynthesis: temperature acclimation of an evergreen tree, Quercus myrsinaefolia, Plant Cell Env. 22 (1999) 841849.

[62] Hollinger D.Y., Optimality and nitrogen allocation in a tree canopy, Tree Physiol. 16 (1996) 627-634.

[63] Horn H.S., The adaptive geometry of trees, Princeton Univ. Press, Princeton, NJ, USA, 1971, 144 pp.
[64] Host G.E., Rauscher H.M., Isebrands J.G., Michael D.A., Validation of photosynthate production in ECOPHYS, an ecophysiological growth process model of Populus, Tree Physiol. 7 (1990) 283-296.

[65] Infante J.M., Rambal S., Joffre R., Modelling transpiration in holm-oak savannah: scaling up from the leaf to the tree scale, Agric. For. Meteorol. 87 (1997) 273-289.

[66] Jarvis P.G., The interpretation of the variations in leaf water potential and stomatal conductance found in canopies in the field, Phil. Trans. R. Soc. London B. 273 (1976) 593-610.

[67] Jarvis P.G., McNaughton K.G., Stomatal control of transpiration: scaling up from leaf to region, Adv. Ecol. Res. 15 (1986) 1-49.

[68] Jiagang L., A theoretical model of the process of rainfall interception in forest canopy, Ecol. Modelling 42 (1988) 111-123.

[69] Jones H.G., Sutherland R.A., Stomatal control of xylem embolism, Plant Cell Environ. 14 (1991) 607-612.

[70] Jordan D.B., Ogren W.L., The CO2/O2 specificity of ribulose 1,5-bisphosphate carboxylase/oxygenase, Planta 161 (1984) 308-313.

[71] Kaimal J.C., Finnigan J.J., Atmospheric boundary layer flows. Their structure and measurement, Oxford Universitry Press, Oxford, 1994, 289 pp.

[72] Kaplan W., Wofsy S., Keller M., Da Costa J.M., Emission of NO and deposition of $\mathrm{O} 3$ in a tropical forest system, J. Geophys. Res. 93 (1988) 1389-1395.

[73] Kellomäki S., Strandman H., A model for the structural growth of young Scots pine crowns based on light interception by shoots, Ecol. Modell. 80 (1995) 237-250.

[74] Kimes D.S., Kirchner J.A., Radiative transfer model for heterogeneous 3D scenes, Appl. Opt. 21 (1982) 4119-4129.

[75] Kimura K., Ishida A., Uemura A., Matsumoto Y., Terashima I., Effects of current-year and previous-year PPFDs on shoot gross morphology and leaf properties in Fagus japonica, Tree Physiol. 18 (1998) 459-466.

[76] Kuuluvainen T., Pukkala T., Effect of crown shape and tree distribution on the spatial distribution of shade, Agric. For. Meteorol. 40 (1987) 215-231.

[77] Lacointe A., Carbon allocation among tree organs: a review of basic processes and representation, Ann. For. Sci. 57 (2000) 521-533.

[78] Le Roux X., Sinoquet H., Vandame M., Spatial distribution of leaf dry weight per area and leaf nitrogen content in relation to local radiation regime within an isolated tree crown, Tree Physiol. 19 (1999a) 181-188.

[79] Le Roux X., Grand S., Dreyer E., Daudet F.A., Parameterization and testing of a biochemically based photosynthesis model for walnut (Juglans regia L.) trees and seedlings, Tree Physiol. 19 (1999b) 481-492.

[80] Lescourret F., Ben Mimoun M., Génard M., A simulation model of growth at the shoot-bearing fruit level. I. Description and parameterization for peach, Eur. J. Agron. 9 (1998) 173-188. 
[81] Leuning R., A critical appraisal of a combined stomatal-photosynthesis model for C3 plants, Plant Cell Env. 18 (1995) 339-355.

[82] Leuning R., Kelliher F.M., De Pury D.G.G., Schulze E.D., Leaf nitrogen, photosynthesis, conductance and transpiration: scaling from leaves to canopies, Plant Cell Environ. 18 (1995) 1183-1200.

[83] Loustau D., Berbigier P., Granier A., El Hadj Moussa F., Interception loss, throughfall and stemflow in a maritime pine stand. I. Variability of throughfall and stemflow beneath the pine canopy, J. Hydrol. 138 (1992) 449-467.

[84] Mäkelä A., Hari P., Stand growth model based on carbon uptake and allocation in individual trees, Ecol. Modell. 33 (1986) 205-229.

[85] Mattingley G.E., Harrje D., Heisler G., The effectiveness of an evergreen windbreak for reducing residential energy consumption. ASHRAE Trans. 85 (1979) 428-444.

[86] McMillen G.G., McGlendon J.H., Leaf angle: an adaptive feature of sun and shade leaves, Bot. Gaz. 140 (1979) 437442 .

[87] McNaughton K.G., Jarvis P.G., Predicting effects of vegetation changes on transpiration and evaporation, in: Kozlowski T.T. (Ed.), Water Deficits and Plant Growth, Vol. VII, Academic Press, New-York, 1983, pp. 1-47.

[88] Meinzer F.C., Stomatal control of transpiration, Trees 8 (1993) 289-294.

[89] Meinzer F.C., Andrade J.L., Goldstein G., Holbrook N.M., Cavelier J., Jackson P., Control of transpiration from the upper canopy of a tropical forest: the role of stomatal, boundary layer and hydraulic architecture components, Plant Cell Env. 20 (1997) 1242-1252.

[90] Minorsky P.V., Temperature sensing by plants: a review and hypothesis, Plant Cell Env. 12 (1989) 119-135.

[91] Monteith J.L., Evaporation and environment, Symp. Soc. Exp. Biol. 19 (1965) 205-234.

[92] Monteith J.L., Solar radiation and productivity in tropical ecosystems, J. Appl. Ecol. 2 (1972) 747-766.

[93] Monteith J.L., A reinterpretation of stomatal responses to humidity, Plant Cell Env. 18 (1995) 357-364.

[94] Monteith J.L., Unsworth M.H., Principles of environmental physics, Edward Arnold, London, 1990, p. 291.

[95] Mott K.A., Parkhurst D.F., Stomatal response to humidity in air and helox, Plant Cell Env. 14 (1991) 509-515.

[96] Myneni R.B., Modeling radiative transfer and photosynthesis in three-dimensional vegetation canopies, Agric. For. Meteorol. 55 (1991) 323-344.

[97] Myneni R.B., Ross J., Asrar G., A review of the photon transport in leaf canopies, Agric. For. Meteorol. 45 (1989) 1153.

[98] Niinemets Ü., Are compound-leaved woody species inherently shade-intolerant? An analysis of species ecological requirements and foliar support costs, Plant Ecol. 134 (1998) 111.

[99] Norman J.M., Jarvis P.G., Photosynthesis in Sitka spruce (Picea sitchensis (bong.) carr.). V. Radiation penetration theory and a test case, J. Appl. Ecol. 12 (1975) 839-878.
[100] Nougier J.P., Méthodes de calcul numérique, Masson, Paris, 1985, 325 pp.

[101] Ogée J., Modélisation lagrangienne des transferts de scalaires entre forêt et atmosphère, DEA Thesis, University of Toulouse III, 1996, $31 \mathrm{pp}$.

[102] Oker-Blom P., The influence of penumbra on the distribution of direct solar radiation in a canopy of Scots pine, Photosynthetica 19 (1985) 312-317.

[103] Oker-Blom P., Kellomäki S., Effect of grouping of foliage on the within-stand and the within-crown light regime: comparison of random and grouping canopy models, Agric. Meteorol. 28 (1983) 143-155.

[104] Pagès L., Doussan C., Vercambre G., Below-ground environment and resource acquisition. Simulation models should include plant structure and function, Ann. For. Sci. 57 (2000) 513-520.

[105] Pearcy R.W., Sunflecks and photosynthesis in plant canopies, Ann. Rev. Plant Physiol. 41 (1990) 421-453.

[106] Pearcy R.W., Yang W., A three-dimensional shoot architecture model for assessment of light capture and carbon gain by understory plants, Oecologia 108 (1996) 1-12.

[107] Pearcy R.W., Sims D.A., Photosynthetic acclimation to changing light environments: scaling from the leaf to the whole plant. in: Caldwell M.M., Pearcy R.W. (Eds.), Exploitation of environmental heterogeneity by plants. Ecophysiological processes above- and belowground, Academic Press, San Diego, 1994, pp. 145-208.

[108] Penman H.L., Natural evaporation from open water, bare soil and grass, Proc. Roy. Soc. London A 194 (1948) 120145.

[109] Perttunen J., Sievänen R., Nikinmaa E., Salminen H., Saarenmaa H., Väkevä J., LIGNUM: a tree model based on simple structural units, Ann. Bot. 77 (1996) 87-98.

[110] Planchais I., Sinoquet H., Foliage determinants of light interception in sunny and shaded branches of Fagus sylvatica (L.), Agric. For. Meteorol. 89 (1998) 241-253.

[111] Raupach M.R., A Lagrangian analysis of scalar transfer in vegetation canopies, Q. J. R. Meteorol. Soc. 113 (1987) $107-120$

[112] Raupach M.R., Turbulent transfer in canopies, in: Russel G., Marshall B., Jarvis P.G. (Eds.), Plant canopies: their growth, from and function, Cambridge University Press, Cambridge, 1989, pp. 41-61.

[113] Rauscher H.M., Isebrands J.G., Host G.E., Dickson R.E., Dickmann D.I., Crow T.R., Michael D.A., ECOPHYS: an ecophysiological growth process model for juvenile poplar, Tree Physiol. 7 (1990) 255-281.

[114] Rôças G., Barros C.F., Scarano F.R., Leaf anatomy of Alchornea triplinervia (Euphorbiaceae) under distinct light regimes in a Brazilian montane Atlantic rain forest, Trees. 11 (1997) 469-473.

[115] Roden J.S., Pearcy R.W., Effect of leaf flutter on the light environment of poplars, Oecologia 93 (1993) 201-207.

[116] Ross J., The radiation regime and architecture of plants stands, Junk Pub., The Hague, 1981, 391 pp. 
[117] Ross J., Sulev M., Saarelaid P., Statistical treatment of the PAR variability and its application to willow coppice, Agric. For Meteorol. 91 (1998) 1-21.

[118] Rutter A.J., Kershaw K.A., Robins P.C., Morton A.J., A predictive model of rainfall interception in forests. I. Derivation of the model from observations in a plantation of Corsican pine, Agric. Meteorol. 9 (1971) 367-384.

[119] Salmon J., Simulation de l'écoulement de la pluie sur des maquettes de plantes, DEA Thesis, University of Pointe-àPitre, 1996, 35 pp.

[120] Shuttleworth W.J., Micrometeorology of temperate and tropical forest, Phil. Trans. R. Soc. Lond. B. 324 (1989) 299-334

[121] Sims D.A., Pearcy R.W., Photosynthetic characteristics of a tropical forest understorey herb, Alocasia macrorrhiza, and a related crop species, Colocasia esculenta grown in contrasting light environments, Oecologia 79 (1989) 53-59.

[122] Sinoquet H., Bonhomme R., Modeling radiative transfer in mixed and row intercropping systems, Agric. For. Meteorol. 62 (1992) 219-240.

[123] Sinoquet H., Le Roux X., Adam B., Améglio T., Daudet F.A., Modélisation de la distribution spatiale du microclimat lumineux, de la transpiration et de la photosynthèse : application à un arbre isolé. in: Bonhomme R., Maillard P. (Eds.), Fonctionnement des peuplements végétaux sous contraintes environnementales, INRA Éditions, 2000, pp. 185-199.

[124] Sperry J.S., Pockmann W.T., Limitation of transpiration by hydraulic conductance and xylem cavitation in Betula occidentalis, Plant Cell Env. 16 (1993) 279-287.

[125] Sprugel D.G., Brooks J.R., Hinckley T.M., Effects of light on shoot geometry and needle morphology in Abies amabilis, Tree Physiol. 16 (1996) 91-98.

[126] Sprugel D.G., Hinckley T.M., Schaap W., The theory and practice of branch autonomy, Ann. Rev. Ecol. Syst. 22 (1991) 309-334.

[127] Stenberg P., Simulations of the effects of shoot structure and orientation on vertical gradients in intercepted light by conifer canopies, Tree Physiol. 16 (1996) 99-108.

[128] Takenaka A., Effects of leaf blade narrowness and petiole length on the light capture efficiency of a shoot, Ecol. Res. 9 (1994a) 109-114.

[129] Takenaka A., A simulation model of tree architecture development based on growth response to local light environment, J. Plant Res. 107 (1994b) 321-330.

[130] Tardieu F., Davies W.J., Root-shoot communication and whole-plant regulation of water flux, in: Smith J.A.C.,
Griffiths H. (Eds.), Water deficits. Plant responses from cell to community, Bios Sci. Publ., Oxford, 1993, pp. 147-162.

[131] Thompson O., Pinker R., Wind and temperature profile characteristics in a tropical evergreen forest in Thailand, Tellus 27 (1975) 562-573.

[132] Thornley J.H.M., Photosynthesis, in: J.H.M. Thornley (Ed), Mathematical models in plant physiology, Academic Press, London, 1976, pp. 92-110.

[133] Thornley J.H.M., Dynamic model of leaf photosynthesis with acclimation to light and nitrogen, Ann. Bot. 81 (1998) 421-430.

[134] Thorpe M.R., Saugier B., Auger S., Berger A., Méthy M., Photosynthesis and transpiration of an isolated tree: model and validation, Plant Cell Env. 1 (1978) 269-277.

[135] Tyree M.T., Sperry J.S., Do woody plants operate near the point of catastrophic xylem dysfunction caused by dynamic water stress? Answers from a model, Plant Physiol. 88 (1988) 574-580.

[136] Valladares F., Allen M.T., Pearcy R.W., Photosynthetic responses to dynamic light under field conditions in six tropical rainforest shrubs occuring along a light gradient, Oecologia 111 (1997) 505-514.

[137] Wang Y.P., Jarvis P.G., Description and validation of an array model: MAESTRO, Agric. For. Meteorol. 51 (1990) 257-280.

[138] Whitehead D., Regulation of stomatal conductance and transpiration in forest canopies, Tree Physiol. 18 (1998) 633-644.

[139] Whitehead D., Grace J.C., Godfrey M.J.S., Architectural distribution of foliage in individual Pinus radiatia D. Don crowns and the effect of clumping on radiation interception, Tree Physiol. 7 (1990) 135-155.

[140] Wilson J.D., Turbulent transport within the plant canopy, in: Estimation of Areal Evapotranspiration, IAHS Publ. No. 177, 1989, pp. 43-80.

[141] Wilson J.D., Shaw R.H., A higher order closure model for canopy flow, J. Appl. Meteorol. 16 (1977) 1197 1205 .

[142] Wong S., Cowan I.R., Farquhar G.D., Stomatal conductance correlates with photosynthetic capacity, Nature 282 (1979) 424-426.

[143] Yamada T., A numerical study of turbulent airflow in and above a forest canopy, J. Meteorol. Soc. Jap. 60 (1982) 439-454.

[144] Zhang H., Nobel P.S., Dependency of $\mathrm{Ci} / \mathrm{Ca}$ and leaf transpiration efficiency on the vapour pressure deficit, Aust. J. Plant Physiol. 23 (1996) 561-568. 